\title{
Hydroclimatic Variability in North-central Mongolia as Inferred from Tree Rings
}

Caroline Leland

West Virginia University

Follow this and additional works at: https://researchrepository.wvu.edu/etd

\section{Recommended Citation}

Leland, Caroline, "Hydroclimatic Variability in North-central Mongolia as Inferred from Tree Rings" (2011). Graduate Theses, Dissertations, and Problem Reports. 536.

https://researchrepository.wvu.edu/etd/536

This Thesis is protected by copyright and/or related rights. It has been brought to you by the The Research Repository @ WVU with permission from the rights-holder(s). You are free to use this Thesis in any way that is permitted by the copyright and related rights legislation that applies to your use. For other uses you must obtain permission from the rights-holder(s) directly, unless additional rights are indicated by a Creative Commons license in the record and/ or on the work itself. This Thesis has been accepted for inclusion in WVU Graduate Theses, Dissertations, and Problem Reports collection by an authorized administrator of The Research Repository @ WVU. For more information, please contact researchrepository@mail.wvu.edu. 


\title{
Hydroclimatic Variability in North-central Mongolia as Inferred from Tree Rings
}

\author{
Caroline Leland \\ Thesis submitted to the \\ Eberly College of Arts and Sciences \\ at West Virginia University \\ in partial fulfillment of the requirements \\ for the degree of \\ Master of Arts \\ in \\ Geography \\ Amy Hessl, Ph.D., Chair \\ Neil Pederson, Ph.D., \\ Brenden McNeil, Ph.D. \\ Department of Geology and Geography \\ Morgantown, West Virginia
}

2011

Keywords: tree rings, Mongolia, climate, dendrochronology

Copyright 2011 Caroline Leland 


\section{ABSTRACT \\ Hydroclimatic Variability in North-central Mongolia as Inferred from Tree Rings Caroline Leland}

The influence of increasing temperatures on hydrologic regimes across Mongolia is difficult to evaluate from a spatial perspective, particularly at fine resolutions. Therefore, networks of tree-ring chronologies are a valuable means of assessing regional and local variability in hydroclimate while placing recent moisture trends in a historical context. Tree-ring data are particularly useful in Mongolia, where instrumental records are spatially and temporally limited. Here, I present two chapters that are essentially related and complement one another. The first chapter seeks to identify tree-growth anomaly regions (i.e. inferred hydroclimatic regions) across north-central Mongolia based on a network of 21 tree-ring chronologies. I applied a rotated principal component analysis (RPCA) to the tree-ring network and identified four tree-growth anomaly regions, which display unique hydroclimatic variability through time. Chapter Two evaluates the tree-growth anomaly regions in terms of ranked drought and pluvial events. From a spatial perspective, these analyses demonstrate the extent of interregional and intraregional hydroclimatic variability across the network; in particular, the results highlight that the Eastern and Western regions of the network are especially unique from one another. Each chapter is presented in a journal article format and consists of its own abstract. 


\section{ACKNOWLEDGMENTS}

I would like to especially thank my advisor and mentor, Dr. Neil Pederson, for his continued support through my graduate career. He always encouraged me to think critically, challenge ideas, and reach towards my full potential. Under his guidance, I developed new appreciations for research, science, and life in general. I would also like to recognize Dr. Amy Hessl for helping me every step of the way and for introducing me to the world of dendrochronology as an undergraduate lab assistant. Thanks also to Dr. Brenden McNeil for his assistance and thoughtful comments on my thesis. My six good friends/labmates, Dr. Stockton Maxwell, Dr. Tom Saladyga, Joshua Wixom, Pete Clark, Brad Breslow, and Nathan Malcomb, were instrumental to my development as a dendrochronologist, and I owe much of my progress to them. Tom deserves a special shout-out for being a great field partner, teacher, and motivator in Mongolia. I also owe a big thanks to Dr. Baatarbileg Nachin, Byambagerel Suran, Uyanga Ariya, and my other Mongolian friends and colleagues for their expertise and generous help during summer fieldwork. Those at the Lamont-Doherty Earth Observatory Tree-ring Lab, particularly Dr. Nicole Davi, were very helpful throughout this entire process, and I thank them for kindly sharing the data that made this project a reality.

I would also like to thank my family and friends. They are a great source of support and motivation and I cannot fully express my gratitude. My loving parents have always encouraged me to be a hard worker but to live a balanced life. My sister, Catherine, is my personal cheerleader and will always be one of my biggest role models. Lastly, a special thanks to Chris, who has always been the voice of reason. 


\section{TABLE OF CONTENTS}

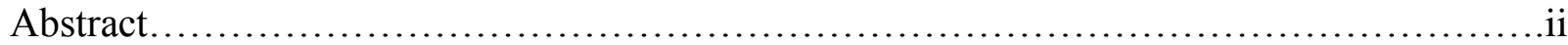

Acknowledgments.............................................................

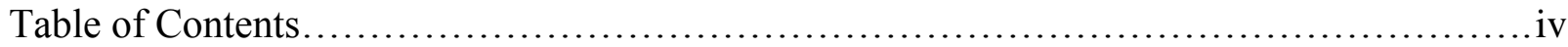

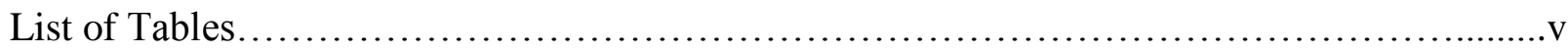

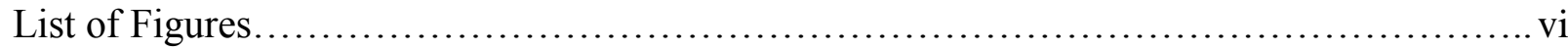

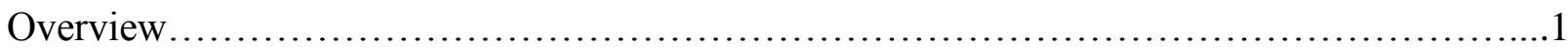

Chapter 1: A Hydroclimatic Regionalization of North-central Mongolia as Inferred from Tree Rings..........................................................................

Chapter 2: The Spatiotemporal Expression of Droughts and Pluvials across North-central Mongolia...................................................................44

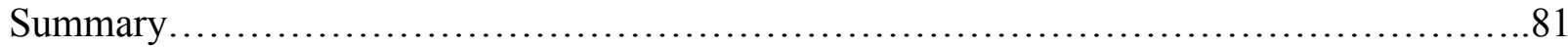

Curriculum Vitae.................................................................... 83 


\section{List of Tables}

Chapter One

Table 1. List of site chronologies in the tree-ring network....................... 29

Table 2. Correlations between tree-growth anomaly regions..................... 30

Table 3. Correlations between streamflow data and regional PC1 scores over the

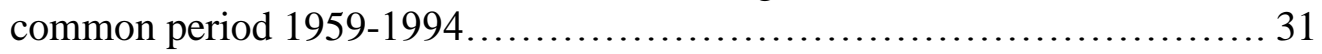

\section{Chapter Two}

Table 1. List of site chronologies in the tree-ring network........................ 68

Table 2. Top-five drought events identified by a runs analysis for each region..... 69

Table 3. Top-five pluvial events identified by a runs analysis for each region...... 69

Table 4. Correlations between tree-growth anomaly regions ...................... 70

Table 5. Cumulative runs analysis drought scores.............................. 70

Table 6. Cumulative runs analysis pluvial scores............................ 70 


\section{List of Figures}

Chapter One

Figure 1. Map of tree-ring chronology network and instrumental data

Figure 2. Maps showing loadings for each varimax factor in the full period (1790-1994).

Figure 3. PC1 scores for each region

Figure 4. Maps showing loadings from the five varimax factors over the early period (1790-1891).

Figure 5. Maps showing loadings from the four varimax factors over the late period (1892-1994)

Figure 6. Ranking of the most severe periods of reduced growth using a 3-year running average........................................................ 38

Figure 7. Ranking of the most severe periods of reduced growth using a 5-year running average.

\section{Chapter Two}

Figure 1. Map of tree-ring chronology network.............................. 71

Figure 2. PC1 scores for each region......................................... 72

Figure 3. Violin plots for each region in $~ 50$-year subsets....................... 73

Figure 4. Maps of top-scoring drought events............................... 74

Figure 5. Maps of top-scoring pluvial events.............................. 75

Figure 6. Growth percentile maps for the years $1995-2002 \ldots \ldots \ldots \ldots \ldots \ldots \ldots \ldots \ldots \ldots$

Figure 7. Eruu River streamflow and PC scores for the Northern region from 1959-2008. 


\section{OVERVIEW}

This thesis consists of two related chapters that explore the potential of a tree-ring network in north-central Mongolia to assess spatiotemporal variability in hydroclimate. A network of 21 tree-ring chronologies, consisting of Siberian Pine (L. sibirica), Scots Pine ( $P$. sylvestris), and Siberian Larch (L. sibirica), was compiled for the following chapters. The network served as the fundamental dataset for all analyses. Many of the chronologies were developed by tree-ring scientists at Lamont-Doherty Earth Observatory and are freely available on the internet (http://www.ncdc.noaa.gov/paleo/treering.html). However, I developed six of the chronologies within the network during the two years of my master's program (at Eastern Kentucky University and West Virginia University), and I was involved in data collection during the summer of 2010. The tree-ring network was used to address the following objectives:

1) Define tree-growth anomaly regions within the network and evaluate their relationship to instrumental streamflow data. (Chapter One)

2) Assess the spatial and temporal characteristics of droughts and pluvials across the tree-growth anomaly regions. (Chapter Two)

Chapter One is titled 'A Hydroclimatic Regionalization of North-central Mongolia as Inferred from Tree Rings.' The idea for this chapter developed after my advisor (Dr. Neil Pederson) and I conducted some exploratory analyses with available tree-ring data from Mongolia. Initially, our goal was to determine if newly collected chronologies within the network could be valuable for inferring climate in a 'new' region of Mongolia that had not yet been fully studied from a paleoclimatic perspective. Then, we noticed that the network, considered as a whole, could provide insight into climatic variability on a much larger scale. I developed the first chapter based on this concept. I applied a rotated principal components 
analysis (RPCA) to define dominant tree-growth anomalies (i.e. tree-growth patterns) across the tree-ring chronology network for the common period of 1790-1994. Essentially, the RPCA identifies chronologies that co-vary similarly over time so that they can be grouped into treegrowth anomaly regions. This method has been applied in multiple studies, however, no published study has yet examined tree-growth anomalies in Mongolia at the spatial scale considered here. After identifying four tree-growth anomaly regions (the Eastern, Western, Northern, and Central regions), I tested their stability in both space and time. The majority of tree-ring chronologies are expected to be drought sensitive, as many of them have been used in previous hydroclimatic reconstructions, however, I validated the connection between the treegrowth anomalies and instrumental records with correlation analyses. Instrumental data is lacking in Mongolia, so I was only able to relate the tree-growth anomalies to three different streamflow records within the network (Selenge, Tuul, and Eruu Rivers) which were relatively short in length. Results suggest that the tree-growth anomaly regions are mostly robust and stable through time, and that they are likely a reflection of hydroclimatic variability across the network. I plan to submit the first chapter to the journal Tree-Ring Research, and it has been formatted accordingly.

Chapter Two is titled "The Spatiotemporal Expression of Droughts and Pluvials across North-central Mongolia", and it incorporates and enhances some of the findings from Chapter One. This chapter is more experimental in terms of the methods that I apply to the tree-ring network. The overall objective was to further explore the four tree-growth anomalies. In the context of this chapter, hydroclimatic variability was inferred from the regional PC scores and the standardized index values of individual tree-ring chronologies. The limitations of this should be considered, especially for examining growth patterns of individual chronologies. I quantified 
major drought and pluvial events from 1790-1994 for each of the four tree-growth anomalies identified in the previous chapter. The drought and pluvial events were examined from a temporal and spatial perspective. I mapped major drought/pluvial events on the chronology-scale across the network using averaged growth-percentiles. I also investigated the spatial expression of the 1999-2002 drought event which was reported as being notably severe across much of Mongolia. Results indicate that there is a relatively high degree of spatial hydroclimatic variability within and between tree-growth anomaly regions, and that the spatial extent of notable drought/pluvial events can vary widely. The Western region appears to be particularly different from the other regions in terms of major hydroclimatic events, but the most obvious differences are between the Western and Eastern regions which were the least correlated from 1790-1994 $(\mathrm{r}=0.026, \mathrm{p}>0.05)$. Interestingly, all regions in the network display similar variability in inferred hydroclimate over time, particularly from 1950-1994, which consisted of generally wetter conditions. This period of analysis, however, does not take into consideration the severe droughts of the late 1990s and early 2000s. In examining the 1999-2002 droughts individually (note: this analysis was conducted only for the Northern region, as most of the chronologies in the other regions were collected prior to 2002), results suggest that this drought event might have not been particularly severe in northern Mongolia, and that the annual drought severity might have differed significantly on local spatial scales. The second chapter was formatted in a similar manner as the first chapter. I hope you enjoy reading my thesis. 


\title{
Chapter 1: A Hydroclimatic Regionalization of North-central Mongolia as Inferred from Tree Rings
}

\author{
Caroline Leland ${ }_{1}^{*}$, Neil Pederson 2 , Nicole Davi 2 , Amy Hessl 1 , Baatarbileg Nachin 3
}

1. Department of Geology and Geography West Virginia University, P.O. Box 6300,

Morgantown, West Virginia 26506, USA. *Corresponding author: carolineleland@ gmail.com

2. Tree-ring Laboratory, Lamont-Doherty Earth Observatory, P.O. Box 1000, 61 Rt. 9W,

Palisades, New York 10964, USA.

3. Tree-ring Laboratory, Department of Forestry, National University of Mongolia, Ulaanbaatar, Mongolia.

To be submitted to: Tree-Ring Research 


\begin{abstract}
In arid and semi-arid regions of the world, such as Mongolia, the future of water resources under a warming climate is of particular concern. The influence of increasing temperatures on precipitation is difficult to predict, as precipitation trends in coming decades could have a high degree of spatial variability. Networks of tree-ring chronologies can been used to evaluate spatial variability in climate while placing recent variability in the context of the past several centuries. In this study, we applied a rotated principal component analysis (RPCA) to a network of 21 tree-ring chronologies across north-central Mongolia from 1790-1994. The RPCA results indicate that the network consists of four tree-growth anomaly regions, or regions with co-varying tree-ring chronologies (the Eastern, Western, Northern, and Central regions). In testing the stability of the tree-growth anomalies with a temporal subset and reduced dataset analysis, we found that the regions remain mostly consistent through time and space. Correlation analyses were then used to illustrate potential linkages between the tree-growth anomalies and streamflow data. This study highlights the extent of spatial variability in hydroclimate across north-central Mongolia and emphasizes the value of tree-ring networks in locations with limited instrumental records.
\end{abstract}

Keywords: tree-growth anomalies, regions, RPCA, network, Mongolia 


\section{Introduction}

Climate change models project increasing temperatures across Asia in coming decades with the most pronounced warming occurring in northern and central Asia (Christensen et al. 2007). Instrumental records from Mongolia suggest that average temperatures have been generally increasing since the 1940s (Batima et al. 2005). Warming temperatures can influence hydrology by increasing evaporation rates, enhancing the water retention capacity of the atmosphere, changing the timing of snowmelt, and altering the severity of floods and droughts (Trenberth et al. 2003). The multiple impacts of increasing temperatures on hydrology, in combination with the local nature of precipitation (Tebaldi et al. 2006), has led to great uncertainty in predicting future hydrologic change at fine resolutions in Asia (Christensen et al. 2007), including Mongolia (Sato et al. 2007a).

Increasing temperatures and uncertainty in regional precipitation trends have led to increased concern over the availability of water in the future. In arid and semi-arid regions, like Mongolia, the impacts of drought could be devastating. Mongolians rely on pastoralism and agriculture as a major component of their culture, economy, and livelihood (Johnson et al. 2006). Therefore, the frequency and intensity of droughts are important considerations in determining the susceptibility of Mongolians to climatic extremes. For example, the droughts of 1999-2002 were linked to significant losses of livestock and had negative impacts on local economies (Siurua and Swift 2002, Batima et al. 2005). The social and economic impacts of drought across Mongolia warrant a better understanding of how hydroclimate, or moisture availability, has varied in the past relative to recent decades.

Although instrumental records provide a basic assessment of recent climate trends across Mongolia (Batima et al. 2005, Endo et al. 2006), the records are temporally and spatially limited. 
Instrumental records are nonexistent in remote regions, and only few records predate the 1940s. Tree-ring reconstructions have been used as a valuable proxy to assess climatic variability prior to instrumental records and to place recent climate anomalies in a historical context (e.g.

Stockton and Jacoby 1976, Grissino-Mayer 1996, Woodhouse 2001, Gray et al. 2004, Cook et al. 1999; 2004; 2010). In Mongolia, several climate reconstructions have been carried out by those involved with the Mongolian American Tree-ring Project (MATRIP), a research collaboration between scientists from Lamont-Doherty Earth Observatory and Mongolia. Both hydrometeorological (Pederson et al. 2001, Davi et al. 2006) and drought reconstructions (Davi et al. 2009, 2010) produced by MATRIP highlight the complexity of hydroclimate across Mongolia and emphasize climatic variability between regions.

Networks of tree-ring chronologies have been used to assist the development of climate reconstructions and to assess spatial patterns of climatic variability. Several studies implement Principal Components Analysis (PCA) to identify regions of co-variation in tree-growth (i.e. tree-growth anomalies) (e.g. LaMarche and Fritts 1971, Brubaker 1980, Meko et al. 1993, Watson and Luckman 2001). Tree-growth anomalies represent unique growth patterns and can typically be linked to one or several drivers of growth, often specific climate variables. Studies examining tree-growth anomalies have been conducted on several different spatial scales. On a broad scale, Meko et al. (1993) delineated tree-growth anomaly regions across the continental United States and discovered that the regions generally coincided with drought regions defined by a PCA of Palmer's Drought Severity Index (PDSI) values. Similar methods were applied by Fang et al. (2010) for reconstructing spatial droughts in central High Asia. Chronology networks spanning smaller, sub-regional scales in North America have also been valuable in uncovering local variation in climate (e.g. Brubaker 1980, Watson and Luckman 2001). In this study, we 
take a fine-scale approach in investigating characteristics of tree-growth anomalies by focusing on north-central Mongolia. This approach is particularly important in Mongolia considering that meteorological stations are spatially limited and there is limited, long-term understanding of local climatic variability. No studies have yet examined tree-growth anomalies at an equivalent, sub-regional spatial scale in this specific part of Asia.

Therefore, we implement a network of 21 tree-ring chronologies to determine the extent of hydroclimatic variability in north-central Mongolia. Specifically, we: 1) assess spatial and temporal characteristics of tree-growth anomalies, 2) determine the stability of tree-growth anomalies over time, and 3) evaluate the potential hydroclimatic signal associated with the treegrowth anomalies. This information could help guide further efforts in developing climate reconstructions for the region.

\section{Materials and Methods}

\subsection{Tree-ring Network}

A network of 21 tree-ring chronologies from north-central Mongolia was compiled for this study (Table 1, Fig. 1). The locations of tree-ring chronologies in the network span $46^{\circ} 47^{\prime}$ $\mathrm{N}$ to $50^{\circ} 09^{\prime} \mathrm{N}$ latitude and $99^{\circ} 52^{\prime} \mathrm{E}$ to $111^{\circ} 41^{\prime}$ E longitude. Elevations range from $\sim 650 \mathrm{~m}$ to 2000 m, and the network includes chronologies from the Khangai and Khentii Mountain ranges. The study area is located mostly within the forest-steppe ecotone, therefore, forests are typically limited to north-facing slopes. The uneven distribution of forest cover mostly explains the irregular distribution of chronologies across the network. Similarly, the tree species represented in the chronologies, $P$. sylvestris, $P$. sibirica, and $L$. sibirica, are not evenly spread 
across the network due to regional species distributions. These tree species were used in this study because they provide the longest known records of tree growth in the study area.

Of the 21 chronologies used in this study, 11 chronologies were developed by those associated with MATRIP. Many of the MATRIP chronologies were used in previous hydroclimatic reconstructions and are known to be drought-sensitive (Pederson et al. 2001, Davi et al. 2006, 2010). We collected ten additional tree-ring chronologies in 2009 and 2010. Most of these chronologies were collected from classic moisture-limited sites with steep slopes or welldrained substrate (Fritts 1976). We targeted old trees at each site (Swetnam and Brown 1992, Pederson 2010), and extracted two increment cores per tree if possible. In some cases where trees had significant heartrot, only one increment core was extracted. This was not a serious limitation as tree replication is often more useful than core replication (Fritts 1976).

In the laboratory, increment cores of new collections were prepared following standard dendrochronological methods (Stokes and Smiley 1968). All tree cores within a site were crossdated visually. Growth rings were measured to an accuracy of $0.01 \mathrm{~mm}$ on a Velmex measuring stage, and visual crossdating was verified with the quality control program COFECHA (Holmes 1983).

Site chronologies were developed using established standardization techniques with the program ARSTAN (Cook 1985). The standardization process removes non-climatic variability in each tree-ring series and averages the detrended ring-widths of all series from a site to reduce the noise of individual trees (Fritts 1976). First, the heteroscedastic variance of each series was stabilized with a data-adaptive power transformation (Cook and Peters 1997, Esper et al. 2003). Then, all of the series were detrended with a linear or negative exponential curve to remove allometric trends in ring-width. For trees in closed-canopy forests, standardizing with a flexible 
curve may help reduce growth patterns related to disturbance and competition (Cook and Peters 1981, Pederson et al. 2004). Therefore, selected series were detrended again with a conservative Friedman supersmoother curve having an $\alpha$ parameter between 6 and 9 (Friedman 1984, Buckley et al. 2010). The Friedman supersmoother curves were applied only to series that displayed obvious suppression and release patterns in ring-widths (Lorimer and Frelich 1989).

In order to account for species differences in serial autocorrelation, we used the residual chronologies for all analyses. However, it should be noted that results here were not significantly different when using standard and ARSTAN chronologies. Biological persistence was removed from the detrended tree-ring series using autoregressive moving average models (Box and Jenkins 1970, Meko 1981) in ARSTAN, and individual series were averaged into a residual site chronology using a bi-weight robust mean. Variances of the residual chronologies were stabilized with either the Keith Briffa or one-third smoothing spline options in ARSTAN.

The expressed population signal (EPS) statistic was calculated for each chronology in 50year segments of overlapping 25-years to determine a common period for all chronologies in the network. The EPS gauges the signal-to-noise ratio of a chronology over time, and it is a useful metric for assessing chronology strength (Cook and Kairiukstis 1990). An EPS of 0.85 has been proposed as an appropriate cut-off criterion for climate reconstructions (Wigley et al. 1984). Therefore, we established the common period as 1790-1994 since all chronologies maintain a between-tree EPS of 0.85 for that full period of time. The only exceptions are Tujyin Nars (TN) and Bugant (BG), which drop to $\sim 0.75$ and $\sim 0.80$ around 1790 , respectively. These chronologies were retained because, despite their slightly lower EPS values, their locations are valuable components of the network. 


\subsection{Instrumental Data}

Streamflow data were used to investigate the relationship between tree-growth anomalies and hydroclimate. The instrumental data was collected from three different stream gauges within the study region: the Selenge (1945), Eruu (1959), and Kherlen (1959) Rivers (Fig. 1). The years in parentheses indicate how far each instrumental record extends back in time. We averaged the June-August values of streamflow for each year to create an annual time-series for comparison against the tree-growth anomalies. The relationships between the tree-growth anomalies and Palmer's Drought Severity Index (PDSI) data (Dai et al. 2004) were also tested, however, the results were similar and are not presented here. The streamflow data are likely more valuable for this study because they provide site-specific and measured values of hydroclimate, whereas the PDSI data consist of interpolated grid-point values across a region with few, limited instrumental records.

\subsection{Methods}

\subsubsection{RPCA and the Development of Regional Time Series}

We performed a varimax rotated principal component analysis (RPCA) over the 17901994 common period of all chronologies to detect tree-growth anomalies across the network. An S-mode PCA was applied to the full network, in which the chronologies are the variables and the individual years are the observations, and all components with an eigenvalue $>1$ were retained for the varimax rotation. Each of the resulting factors represents an individual tree-growth anomaly that is present within the network of chronologies. Therefore, chronologies with a high loading on a particular factor are associated with the same tree-growth anomaly and are expected to co-vary similarly over time. The varimax rotation eases interpretation of results as the 
variables load strongly on to one or few orthogonal factors (Richman 1986). Some studies have suggested that the orthogonality requirement of a varimax rotation might not be realistic (Meko et al. 1993, Cook et al. 1999), and that oblique rotations provide more stable results (White et al. 1991). However, we found that an oblique rotation of the dataset, which allows some correlation between factors, did not alter the general outcome (results not shown).

Chronology loadings for each factor were mapped in order to investigate the spatial characteristics of the tree-growth anomalies. Chronologies sharing a common growth anomaly are typically clustered into 'regions', which suggests that similar variables drive growth (LaMarche and Fritts 1971, Brubaker 1980, Watson and Luckman 2001). Therefore, each region can be represented by a general tree-growth anomaly pattern. Here, each chronology was assigned to a tree-growth anomaly, and corresponding region, based on its RPCA factor loadings; the factor that each chronology loaded highest onto determined the tree-growth anomaly (region) to which it was assigned. Then, we produced an individual time-series for each tree-growth anomaly by performing an unrotated PCA only on the chronologies assigned to each region. The first component scores (PC1) for each region were retained as means of summarizing annual growth from 1790-1994, where negative scores indicate years of below-average growth and positive scores indicate above-average growth (Brubaker 1980). The PC1 scores from the unrotated PCAs were preferred over the factor scores from the original RPCA so that the regional time-series would not be orthogonally-related.

\subsubsection{Testing the Stability of Tree-growth Anomaly Regions}

The temporal stability of the tree-growth anomaly regions was tested by running separate RPCAs on temporal subsets of the common period. The common period was split into roughly 
equal halves (1790-1891 for the early period; 1892-1994 for the late period). For each temporal subset, an RPCA was conducted on the full 21-chronology network using the same methods as detailed for the full common period analysis. The chronology loadings were mapped for each factor, and all chronologies were assigned to a tree-growth anomaly region based on their loadings. By comparing the spatial results of chronology loadings for the temporal subsets with the full common period analysis, we could gauge the relative stability of the tree-growth anomaly regions through time.

The spatial stability of the tree-growth anomaly regions over the full common period (1790-1994) was then evaluated with a reduced dataset analysis. An uneven spatial distribution of chronology sites can potentially bias the results of a PCA (Karl and Koscielny 1982). Some chronologies in the network are spatially clustered and highly intercorrelated (e.g. KLL and KLP, IR and ONG), whereas others are isolated and exhibit unique growth patterns. To account for this bias, gridding of tree-ring data has been proposed as an alternative method of identifying spatial patterns of tree-growth anomalies (Meko et al. 1993). Gridding was not appropriate for this dataset due to large gaps within the network. However, we addressed potential biases in the original PCA by applying an additional RPCA to a reduced dataset (Watson and Luckman 2001). The goal of the reduced dataset analysis is to ensure that the PCA results from the full dataset are not driven by spatially clustered (i.e. highly correlated) chronologies. Therefore, a reduced dataset was produced by applying a k-means cluster analysis to the network. Clusters of correlated chronologies were identified, and a single time series was produced for each cluster by combining the correlated chronologies with an unrotated PCA and extracting the PC1 scores. Then, an RPCA was applied to the reduced dataset, following the methods described for the full 
network analysis, to evaluate the spatial stability of the regions without clustered and strongly correlated chronologies.

\subsubsection{Evaluating the Hydroclimatic Signal}

The last objective was to determine if the tree-growth anomalies from the full common period and full network RPCA reflect spatial variability in hydroclimate across the study area. We ran multiple correlation analyses between the regional growth-anomalies (i.e. PC1 scores) and instrumental data. The growth anomaly of each region was compared against the averaged June-August values for each year of the streamflow data (Selenge, Eruu, and Kherlen Rivers). We considered only the summer months in order to capture the majority of the growing season. The comparisons were restricted to 1959-1994, as the Eruu and Kherlen River streamflow data only extended back to 1959 .

\section{Results}

\subsection{Regionalization}

A PCA was applied to all 21 chronologies in the network for the common period 17901994, and four components with an eigenvalue $>1$ were identified and subjected to a varimax rotation (Appendix A). A total of $65 \%$ of the variance in the dataset was explained by the four varimax factors. In plotting the chronology loadings of each varimax factor on a map (Fig. 2), it is apparent that the factors are divided into four tree-growth anomaly regions: Eastern (VF1), Western (VF2), Northern (VF3), and Central (VF4). All regions consist of at least two different species, except for the Northern region, which is comprised of only P. sylvestris. We did not 
depict negative loadings on the map as they were all near zero. Therefore, there are likely no inverse interactions amongst the regions from 1790-1994.

Each chronology was assigned to one of the four regions based on its RPCA factor loadings. Orkhon Gol (OGH) and Narstyin Davaa (NTD) were the only chronologies that did not exhibit a strong favor towards one particular region. In the case of OGH, this is probably related to its isolated location relative to the other chronologies. OGH loaded slightly higher with the Central region compared to the Western region (factor loadings of 0.49 and 0.39 , respectively), therefore we included it with the Central region. Further, the OGH site characteristics more closely resemble the forest steppe ecotone of the Central region. The NTD varimax factor loadings for the Central and Northern regions were also closely tied ( 0.43 and 0.55 , respectively) due to its intermediary location. We included NTD with the Northern region as it loaded slightly higher with that tree-growth anomaly.

After assigning all chronologies to a region (i.e. tree-growth anomaly), the single timeseries (PC1) scores for each region was produced (Fig. 3). In comparing pairs of regional time series, the Northern and Central regions were the most highly correlated, and the Western region was the most statistically unique from all of the others (Table 2).

\subsection{Stability Analysis}

\subsubsection{Temporal Subsets}

Both the early (1790-1891) and late (1892-1994) period RPCAs (Figs. 4 and 5, respectively) exhibit a similar spatial patterning of factors (i.e. tree-growth anomaly regions) as the full period. The late period (1892-1994) RPCA is more similar to the full period RPCA. Four components (eigenvalue $>1$ ) were retained for a varimax rotation in the late period (Appendix 
B), and the four rotated factors explained a cumulative $69 \%$ of the variance in the dataset. Based on the spatial distribution of loadings, the four varimax factors of the late period correspond to the regions identified in the full common period analysis (Eastern, Western, Northern and Central), and all of the chronologies loaded the highest on the same respective regions as in the full period. Interestingly, the early period (1790-1891) RPCA yielded slightly different results than the full and late period analyses. Five components with an eigenvalue $>1$ were retained (Appendix C), and a cumulative $69 \%$ of the variance was explained by the varimax-rotated factors. The most notable difference was that the Western region split into two separate factors (VF2 and VF5) during the early period. However, the Eastern, Northern, and Central regions of the full/late period analyses remained essentially the same. The only exception was that NTD loaded highest with the Northern region as opposed to the Western region of the full period analysis.

\subsubsection{Reduced Dataset}

We extracted 10 groups from the k-means cluster analysis and verified the groups with a visual inspection of the map. The assignment of 10 groups was appropriate because it: a) effectively grouped chronologies that were found to be highly correlated and were noticeably clustered on the map, and b) retained individual chronologies that were spatially isolated and unique from other chronologies. Five groups represented single chronologies (e.g. OGH was the only chronology in Cluster 2), whereas each of the other five groups were clusters of correlated chronologies (e.g. ZHU and NTD were grouped together in Cluster 6). Cluster assignments for each chronology can be found in Table 1. A single time series was produced for each of the five 
groups that consisted of more than one chronology by applying a PCA to the grouped chronologies and extracting the leading component scores.

After conducting an RPCA of the 10 groups from the cluster analysis, three components were retained and $65 \%$ of the variance in the reduced dataset was explained (Appendix D). The three varimax factors correspond to the Eastern, Northern, and Western regions of the full dataset. The main cluster of chronologies in the Central region $(\mathrm{MH}, \mathrm{TJ}, \mathrm{ZM})$ does not produce its own component in the reduced dataset analysis at the eigenvalue $>1$ cut-off criterion. The OGH chronology, which barely loaded highest on to the Central region in the full dataset, loaded highest with the Western region in the reduced dataset analysis. However, at an eigenvalue of 0.91, a fourth component was retained and the Central region was reintroduced. The OGH chronology and the Central region ( $\mathrm{MH}, \mathrm{TJ}$, and $\mathrm{ZM}$ ) cluster loaded highest on to the fourth component.

\subsection{Comparison with Instrumental Data}

Correlation analyses indicate that there are statistically significant relationships between the regional tree-growth anomalies and instrumental data (Table 3). In many cases, a single growth-anomaly is strongly correlated with multiple streamflow records across the network, however, the correlations generally decline as a function of increasing distance between the streamflow record and tree-growth anomaly region.

As expected, the Eastern region tree-growth anomaly correlated the highest with streamflow data from the easternmost river in the network (Kherlen River; $r=0.43, p<0.05$ ). The Western region tree-growth anomaly correlated strongly with the westernmost river in the network (Selenge River; $\mathrm{r}=0.48, \mathrm{p}<0.05$ ), however, it correlated slightly better with the Eruu 
River to the east of the Western tree-growth anomaly region $(\mathrm{r}=0.52, \mathrm{p}<0.05)$. The Northern growth anomaly is the most associated with the Eruu River $(r=0.68, \mathrm{p}<0.05)$, whereas the Central growth anomaly correlated the highest with the Kherlen River $(r=0.59, \mathrm{p}<0.05)$.

\subsection{Extreme Years}

The relationship between tree-growth anomalies and hydroclimate suggests that the marker years of each tree-growth anomaly (or the lowest scores of each component) could be indicators of drought in each region. We ranked the lowest 20 component scores (on a 3-year and 5-year running adjacent-average) in order to determine the most severe periods of reduced growth (Figs. 6 and 7).

In comparing the four tree-growth anomaly regions, some potential periods of drought (i.e. periods of low component scores) are coherent across all or some regions, while other periods of severe drought are unique to single regions. The mid-to-late 1970s was a period of reduced growth for all of the regions; all of the streamflow records also indicate lower than average flow values at that time. Other periods of potential drought across all regions include early 1900 and the mid-to-late-1920s. Conversely, there are periods of time in which only one or two regions express severely reduced growth. The most noticeable example of this is the 1800s, in which the Western region (composed of five chronologies) experienced two long-term events of reduced growth ( 1810-1826 and $\sim 1855-1865)$ that were unparalleled in other regions.

\section{Discussion}

Using a network of 21 tree-ring chronologies, we have found four distinct hydroclimatic regions in north-central Mongolia, a region that is well-populated, important for agriculture 
(Wiens 1951), and has not yet been fully studied from a paleoclimatic perspective. Considering that chronologies with different characteristics (i.e. species representation, elevation, forest histories, etc.) are associated with the same tree-growth anomaly region suggests that a largerscale force is influencing the regional tree-growth patterns. Similar to the results of other studies (e.g. Brubaker 1980, Meko et al. 1993, Watson and Luckman 2001), we have shown that the spatial patterns of tree-growth anomalies likely reflect climatic variability across the network.

\subsection{Tree-growth Anomalies}

The four tree-growth anomaly regions (Eastern, Western, Northern, and Central) display distinct growth patterns over time, although all regions are generally correlated with one another. The Western region is the most dissimilar from other regions as it had much weaker correlations with other tree-growth anomalies across the study area. The uniqueness of the Western region, in particular, might be attributable to orographic effects. The Western region is located in the Khangai Mountain range and is generally higher in elevation, whereas the other regions to the east are more closely associated with the Khentii Mountain range. Studies have emphasized that the Khangai and Khentii mountain ranges are climatically different, in terms of both cloud frequency (Sato et al. 2004), and summer precipitation patterns (Kim et al. 2011). The findings from these studies support the strong differences between the Eastern and Western tree-growth anomalies that were found here.

All tree-growth anomaly regions remained consistent during the early and late temporal subsets, except for the Western region, which was split into two separate regions (i.e. components) during the early period (1790-1891). This result is not surprising considering that the Western region has a large spatial extent relative to other regions in the network, and it 
includes chronologies that are particularly isolated from others and are separated by variable terrain (e.g. UU and SM). In congruence with our findings, some studies have suggested that the period of analysis could influence the locations or numbers of regions identified by an RPCA (Cook et al. 1992, Meko et al. 1993). It is possible that the additional component in the early period could reflect a natural shift in precipitation patterns that resulted in two unique treegrowth anomalies within the Western region. For example, Watson and Luckman (2001) suggested that changes in tree-growth anomaly sub-regions over time in the Southern Canadian Cordillera could be attributed to temporal changes in large-scale atmospheric circulation anomalies. Circulation anomalies influencing precipitation in north-central Mongolia are complex. Potential influence from synoptic-scale disturbances, such as the Asian summer monsoon (Sato et al. 2007b) and the El-Nino Southern Oscillation (Davi et al. 2010) are dynamic, and could directly affect the instability of the Western region over time. Therefore, further analyses are required to evaluate potential synoptic-scale disturbances that might be influencing the network, and the Western region in particular.

In testing the influence of chronology clusters in the reduced dataset analysis, results suggest that the tree-growth anomaly regions remain mostly consistent over the common period (1790-1994) after chronology clusters are removed. It was expected that the Central region's importance might decline in the reduced dataset RPCA considering we condensed the entire region to only one variable. However, the importance of the Central region was most likely elevated due to the clustering of the three central chronologies in the full dataset (MH, TJ, and ZM). Considering that the Central region was present in a fourth eigenvector, the analysis indicates that it still might be an important and distinct tree-growth anomaly region in the network. 
While the stability analyses highlight the robustness of the tree-growth anomaly regions, it should be noted that these results could be unique to the spatial scale of the study. Similar to issues arising from the Modifiable Areal Unit Problem (MAUP) (O’Sullivan and Unwin 2003), a change in the spatial extent of the study area, or the number of chronologies in the network, could potentially change the bounds or number of tree-growth anomaly regions identified by an RPCA. The variation in tree-growth anomalies is a continuous phenomenon across the landscape and the RPCA only identifies the most representative tree-growth anomalies from the chronologies that are available. Nonetheless, the tree-growth anomalies identified herein are an important foundation for assessing broad-scale growth patterns across north-central Mongolia. In future studies, they could be valuable for understanding the influences of atmospheric forcings on regional and local spatial scales.

\subsection{Hydroclimate Analysis}

Spatial distinctions of the tree-growth anomaly regions were not as evident in comparisons with streamflow data. Although the tree-growth anomalies generally correlated the highest with streamflow data nearest to their respective regions, the Western region correlated highest with the Eruu River despite its closer proximity to the Selenge River. The difference in correlation was marginal, however, and it is not a surprising result considering that the Western region is spatially expansive and includes some chronologies located near the Eruu streamflow gauge. Even though the correlations between the tree-growth anomaly regions and the streamflow data are mostly logical from a spatial perspective, the spatial relationships might have been stronger if the streamflow records extended further back in time. This is likely the 
case because many of the obvious differences between the tree-growth anomalies occurred prior to the common period of instrumental records (refer to "Extreme Years" discussion below).

\subsection{Extreme Years}

In ranking extreme years, the regional differences in drought patterns through time become evident (Figs. 6 and 7). Results from the Eastern and Western regions essentially mimic the findings of the Kherlen and Selenge reconstructions, respectively (Pederson et al. 2001, Davi et al. 2006). This is expected considering that many of the chronologies incorporated in this study were also used in developing the reconstructions. As discussed in the Davi et al. (2006) study, the most prominent regional difference between the Selenge and Kherlen River reconstructions took place during the late 1700s. The Western region (Selenge) was wet, whereas the Eastern region (Kherlen) was dry. While our analysis only extends back to 1790 , this trend is still apparent (Fig. 3). Our results also highlight the two long-term events of reduced growth $(\sim 1810-1826$ and $\sim 1855-1865)$ that are unique to the Western region, though this trend is more obvious in the 5-year running average (Fig. 7) than the 3-year running average results (Fig. 6).

More importantly, the ranking results presented here emphasize the distinctive nature of the Northern and Central regions, which have not yet been fully explored in other studies. These regions share some periods of reduced growth with other regions in the network, most notably in the early 1900s and the late 1970s. Some differences arise in the early 1920s and the 1950s, when only the Northern region expresses severely reduced growth. Similarly, the Central region displays a general stability prior to the 1830 s (i.e. no extreme years from $\sim 1790-1834$ ) that is not found in other regions. The results of regional rankings in this study further supports some 
spatial variability in drought patterns across the network, and emphasizes the potential for additional climate reconstructions associated with the Northern and Central regions.

\section{Conclusion}

This study introduces four tree-growth anomaly regions across north-central Mongolia based on a network of 21 tree-ring chronologies. These regions were found to be mostly stable with a temporal subset and reduced dataset analysis. Further, the tree-growth anomalies exhibited a statistically significant relationship with instrumental climate variables, suggesting that they are reflections of hydroclimatic variability across the network. Results here show that a network of chronologies is an important means of evaluating local hydroclimatic variability, particularly in locations where instrumental records are spatially and temporally limited. It is likely that the tree-growth anomalies identified in the Northern and Central regions of this study are climatically unique. Therefore, there is great potential in developing hydroclimatic reconstructions for those parts of the network. The tree-growth anomalies discussed here are a foundation for placing hydroclimatic variability in a spatiotemporal context. However, future studies might focus on the potential mechanisms and forcings behind hydroclimatic variability in the four tree-growth anomaly regions across north-central Mongolia.

\section{Acknowledgments}

This research was funded by the National Science Foundation (Grant \# 0816700). We would like to thank our Mongolian colleagues and those from the tree-ring lab at Lamont-Doherty Earth Observatory for providing helpful guidance and expertise. Specifically, we would like to thank Baatarbileg Nachin, Ed Cook, Byambagerel Suran, Uyanga Ariya, and Thomas Saladyga. 


\section{References}

Batima, P., L. Natsagdorj, P. Gombluudev, and B. Erdenetsetseg, 2005. Observed climate change in Mongolia. Assessments and Adaptations to Climate Change (AIACC) Working Paper 12: 1-26 (www.aiaccproject.org).

Box, G. E. P., and G. M. Jenkins, 1970. Time Series Analysis: Forecasting and Control. HoldenDay, 553 pp.

Brubaker, L. B., 1980. Spatial patterns of tree growth anomalies in the Pacific Northwest. Ecology 61: 798- 807.

Buckley, B. M., K. J. Anchukaitis, D. Penny, R. Fletcher, E. R. Cook, M. Sano, L. C. Nam, A. Wichienkeeo, T. T. Minh, and T. M. Hong, 2010. Climate as a contributing factor in the demise of Angkor, Cambodia, Proceedings of the National Academy of Sciences of the United States of America, 107(15): 6748-6752.

Christensen J. H., B. Hewitson, A. Busuioc, A. Chen, X. Gao, I Held, R. Jones, R. K. Kolli, W.T. Kwon, R. Laprise, V. Maga na Rueda, L Mearns, C.G. Men’endez, J.R“ais“anen, A. Rinke, A. Sarr, P. Whetton, 2007. Regional climate projections. In Climate Change 2007: The Physical Science Basis, Contribution of Working Group I to the Fourth Assessment Report of the Intergovernmental Panel on Climate Change, Solomon S, Qin D, Manning M, Chen Z, Marquis M, Avery KB, Tignor M, Miller HL (eds). Cambridge University Press: Cambridge, New York.

Cook, E.R. and K. Peters, 1981. The smoothing spline: A new approach to standardizing forest interior tree-ring width series for dendroclimatic studies. Tree-Ring Bulletin 41: 45-53.

Cook, E.R.,1985. A time-series analysis approach to tree-ring standardization. PhD dissertation, The University of Arizona Press, Tucson, $171 \mathrm{pp}$.

Cook, E.R., and L.A. Kairiukstis, eds., 1990. Methods of Dendrochronology: Applications in the Environmental Science. Boston, MA: Kluwer Academic Publishers.

Cook, E.R., D.W. Stahle, M.K. Cleaveland, 1992. Dendroclimatic evidence from eastern North America. Climate since A.D. 1500, R.S. Bradley and P.D. Jones, Eds., Routledge: 331348.

Cook E.R. and K. Peters, 1997. Calculating unbiased tree-ring indices for the study of climatic and environmental change. The Holocene 7: 361-370.

Cook, E.R., D.M Meko, D.W. Stahle, M.K. Cleaveland, 1999. Drought reconstructions for the continental United States. Journal of Climate 12: 1145-1162. 
Cook, E.R., C.A. Woodhouse, C.M. Eakin, D.M. Meko, D.W. Stahle, 2004. Long-term aridity changes in the western United States. Science 306: 1015-1018.

Cook, E.R., K.J. Anchukaitis, B.M. Buckley, R.D. D’Arrigo, G.C. Jacoby, W.E. Wright, 2010. Asian monsoon failure and megadrought during the last millennium. Science 328: 486489.

Dai, A. K.E.Trenberth, T.Qian., 2004. A global dataset of Palmer Drought Severity Index for 1870-2002: Relationship with soil moisture and effects of surface warming. American Meteorological Society 5: 1117-1130.

Davi, N.K., G.C. Jacoby, A.E. Curtis and B. Nachin, 2006. Extension of drought records for central Asia using tree-rings: west-central Mongolia. Journal of Climate 19:288-299.

Davi, N.K., G. Jacoby, R. D’Arrigo, N. Baatarbileg, L. Jinbao, A.E. Curtis, 2009. A tree-ringbased drought index reconstruction for far-western Mongolia: 1565-2004. International Journal of Climatology, 29: 1508-1514.

Davi, G. Jacoby, K. Fang, J. Li, R. D’Arrigo, N. Baatarbileg, D. Robinson, 2010. Reconstructing drought variability for Mongolia based on large-scale tree-ring network: 1520-1993. Journal of Geophysical Research, 115, D22103, doi:10.1029/2010JD013907.

Endo, N., T. Kadota, J. Matsumoto, B. Ailikun, T. Yasunari, 2006. Climatology and trends in summer precipitation characteristics in Mongolia for the period 1960-1998. Journal of the Meteorological Society of Japan 84(3): 543-551.

Esper,J. S. G. Shiyatov, V. S. Mazepa, R. J. S. Wilson, D. A. Graybill, and G. Funkhouser, 2003. Temperature-sensitive Tien Shan tree-ring chronologies show multi-centennial growth trends. Climate Dynamics 21: 699-706.

Fang, K., N. Davi, X. Gou, F. Chen, E. Cook, J. Li, R. D’Arrigo, 2010. Spatial drought reconstructions for central High Asia based on tree rings. Climate Dynamics 35: 941-951, doi:10.1007/s00382-009-0739-9.

Friedman J.H., 1984. “A Variable Span Smoother”, Technical Report LCS5, Stanford University, Dept. of Statistics.

Fritts, H. C., 1976. Tree Rings and Climate. New York, NY: Academic Press.

Gray, S.T., S.T. Jackson, J.L. Betancourt, 2004. Tree-ring based reconstructions of interannual to decadal scale precipitation variability for northeastern Utah since 1226 A.D. Journal of the American Water Resources Association 40: 947-960. 
Grissino-Mayer, H.D., 1996. A 2129-year reconstruction of precipitation for northwestern New Mexico, USA. Tree Rings, Environment, and Humanity: Proceedings of the International Conference: Tucson, Arizona, 17-21 May 1994, Radiocarbon, 191-204.

Holmes, R. L., 1983. Computer assisted quality control in tree-ring dating and measurement. Tree-ring Bulletin 43: 69-78.

Johnson, D.A., D.P. Sheehy, D. Miller, and D. Damiran, 2006. Mongolian rangelands in transition. Secheresse 17(1-2): 133-141.

Karl, T. R., and A. J. Koscielny, 1982. Drought in the United States. Journal of Climatology 2: 313-329.

Kim, B.S., S.Z. Hossein, G. Choi, 2011. Evaluation of temporal-spatial precipitation variability and prediction using seasonal ARIMA Model in Mongolia. KSCE Journal of Civil Engineering 15(5): 917-925.

LaMarche, V.C., Jr, H.C. Fritts, 1971. Anomaly patterns of climate over the western United States, 1700-1930., derived from principal component analysis of tree-ring data. Monthly Weather Review 99: 138-142.

Lorimer, C.G., and L.E. Frelich, 1989. A methodology for estimating canopy disturbance frequency and intensity in dense temperate forests. Canadian Journal of Forest Research 19: 651-663.

Meko, D. M., 1981. Applications of Box-Jenkins methods of time series analysis to the reconstruction of drought from tree rings. Ph.D. dissertation, The University of Arizona, $149 \mathrm{pp}$.

Meko, D., E.R. Cook, D.W. Stahle, C.W. Stockton, M.K. Hughes, 1993. Spatial patterns of treegrowth anomalies in the United States and Southeastern Canada. Journal of Climate 6: 1773-1786.

O’Sullivan, D., Unwin, D.J., 2003. Geographic Information Analysis, Wiley, Hoboken, NJ.

Pederson, N., G.C. Jacoby, R.D. D’Arrigo, E.R. Cook, and B. Buckley, C. Dugarjav, R. Mijiddorj, 2001. Hydrometeorological reconstructions for northeastern Mongolia derived from tree-rings: 1651-1995. Journal of Climate 14:872-881.

Pederson, N., E.R. Cook, G.C. Jacoby, D.M. Peteet, K.L. Griffin, 2004. The influence of winter temperatures on the radial growth of six northern range margin tree species. Dendrochronologia 22: 7-29.

Pederson, N., 2010. External characteristics of old trees in the eastern deciduous forest. Natural Areas Journal 30(4): 396-407. 
Richman, M. B., 1986. Rotation of principal components. Journal of Climatology 6: 293-335.

Sato, T., F. Kimura, A. Kitoh, 2004. Cloud frequency in eastern Mongolia and its relation to orography. Proceedings of the Third International Workshop on Terrestrial Change in Mongolia, Ulan Bator, 107-109.

Sato, T., F. Kimura, A. Kitoh, 2007a. Projection of global warming onto regional precipitation over Mongolia using a regional climate model. Journal of Hydrology 333: 144-154.

Sato, T. M. Tsujimura, T. Yamanaka, H. Iwasaki, A. Sugimoto, M. Sugita, F. Kimura, G. Davaa, D. Oyunbaatar, 2007b. Water sources in semiarid northeast Asia as revealed by field observations and isotope transport model. Journal of Geophysical Research 112: D17112, doi: 10.1029/2006JD008321.

Siurua, H. and J. Swift, 2002. Drought and zud but no famine (yet) in the Mongolian herding economy. IDS Bulletin, 33(4), 88-97.

Stockton, C. and G. Jacoby, 1976. Long-term surface water supply and streamflow levels in the upper Colorado River Basin. Lake Powell Research Project Bulletin No. 18, Institute of Geophysics and Planetary Physics, University of California, Los Angeles, 70.

Stokes, M. and T. Smiley, 1968. An introduction to tree-ring dating, Tucson, AZ: University of Arizona Press.

Swetnam, T. W., and P. M. Brown, 1992. Oldest known conifers in the Southwestern United States: Temporal and spatial patterns of maximum age. In: M. K Kaufmann, W.H. Moir, and K 1. Bassett, tech. coords., Old Growth Forests in the Southwest an Rocky Mountain Regions, Proceedings of a Workshop, March 9-13, 1992, Portal, Arizona. USDA Forest Service General Technical Report RM-213:24-38.

Tebaldi, C, K. Hayhoe, J. M. Arblaster, G.A.Meehl, 2006. Going to the extremes: an intercomparison of model-simulated historical and future changes in extreme events. Climatic Change 76: 185-211.

Trenberth, K.E., A. Dai, R.M. Ramussen, D. B. Parsons, 2003. The changing character of precipitation. Bulletin of the American Meteorological Society 84: 1205-1217, doi: 10.1175/BAMS-84-9-1205.

Watson, E. and B.H. Luckman, 2001. The development of a moisture-stressed tree-ring chronology network for the southern Canadian Cordillera. Tree-Ring Research 57: 149168.

White, D., M. Richman, and B. Yarnal, 1991. Climate regionalization and rotation of principal components. International Journal of Climatology 11, 1-25. 
Wiens, H.J., 1951. Geographical limitations to food production in the Mongolian Peoples Republic. Annals of the Association of American Geographers 41 (4): 348-369.

Wigley, T.M.L., K.R. Briffa, and P.D. Jones, 1984. On the average value of correlated time series, with applications in dendroclimatology and hydrometeorology. Journal of Applied Meteorology, 23: 201-213.

Woodhouse, C.A., 2001. A tree-ring reconstruction of streamflow for the Colorado Front Range. Journal of the American Water Resources Association 37: 561-569. 
Table 1. List of site chronologies in the tree-ring network. Asterisks indicate the new chronology collections (collected in 2009 and 2010), which have not yet been implemented in other studies.

\begin{tabular}{l|l|c|l|c|c|c}
\hline SITE NAME & CODE & ALT $(\mathbf{m})$ & \multicolumn{1}{c}{ SPECIES } & \# TREES & YEARS & CLUSTER \\
\hline Bugant* & BG & 1027 & P. sylvestris & 19 & $1730-2008$ & 5 \\
Dadal & DR & 1020 & P. sibirica & 15 & $1704-2001$ & 10 \\
Delger Khan Uul* & DKH & 1247 & P. sylvestris & 13 & $1710-2009$ & 5 \\
Dulaankhan* & DKN & 1180 & P. sylvestris & 20 & $1653-2008$ & 5 \\
Inferno Ridge & IR & 900 & P. sibirica & 19 & $1692-1996$ & 10 \\
Khorgo Lava Larch & KLL & 2060 & L. sibirica & 39 & $1340-2000$ & 1 \\
Khorgo Lava Pine* & KLP & 2077 & P. sibirica & 13 & $1422-2009$ & 1 \\
Manzshir Hiid & MH & 1755 & P. sibirica & 8 & $1505-1994$ & 7 \\
Narstain Davaa* & NTD & 1548 & P. sylvestris & 11 & $1740-2008$ & 6 \\
Onon Gol & ONG & 1012 & L. sibirica & 16 & $1576-2001$ & 10 \\
Orkhon Gol Hushree* & OGH & 1829 & L. sibirica & 15 & $1503-2009$ & 2 \\
Suulchyin Medee & SM & 1419 & L. sibirica & 15 & $1557-2002$ & 3 \\
Shaamar Mahan Nars* & SMN & 650 & P. sylvestris & 9 & $1770-2008$ & 5 \\
Terelj & TJ & 1669 & L. sibirica & 16 & $1590-2002$ & 7 \\
Tujyin Nars* & TNC & 750 & P. sylvestris & 12 & $1731-2008$ & 5 \\
Uglugchiin Herem* & UGH & 1416 & P. sylvestris & 9 & $1705-2009$ & 8 \\
Under Ulaan & UU & 1545 & L. sibirica & 15 & $1510-2002$ & 4 \\
Urgun Nars & UN & 1070 & P. sylvestris & 15 & $1651-1996$ & 9 \\
Zurkh Uul* & ZHU & 1228 & P. sylvestris & 14 & $1714-2009$ & 6 \\
Zuun Mod & ZM & 1415 & L. sibirica & 26 & $1582-2000$ & 7 \\
Zuun Salaa Mod & ZSM & 1900 & L. sibirica & 20 & $1513-2001$ & 1 \\
\hline
\end{tabular}


Table 2. Correlations between tree-growth anomaly regions. Asterisks indicate that the correlation coefficient is significant at the $\mathrm{p}<0.05$ level.

\begin{tabular}{l|cccc}
\hline & Eastern & Western & Northern & Central \\
\hline Eastern & --- & & & \\
Western & 0.026 & --- & & \\
Northern & $0.383^{*}$ & $0.251^{*}$ & --- & \\
Central & $0.380^{*}$ & $0.238^{*}$ & $0.439 *$ & -- \\
\hline
\end{tabular}


Table 3. Correlations between streamflow data and regional PC1 scores over the period 1959-1994. Asterisks indicate that the correlation coefficient is significant at the $p<0.05$ level.

\begin{tabular}{l|c|c|c|c}
\hline River & Eastern & Western & Northern & Central \\
\hline Selenge & 0.09 & $0.48^{*}$ & $0.45^{*}$ & 0.16 \\
Eruu & $0.35^{*}$ & $0.52^{*}$ & $0.68^{*}$ & $0.40^{*}$ \\
Kherlen-Underkhaan & $0.43^{*}$ & $0.47^{*}$ & $0.48^{*}$ & $0.59^{*}$ \\
\hline
\end{tabular}




\section{List of Figures}

Fig. 1. Map of tree-ring chronology network and instrumental data. The light gray represents forest cover. $\mathrm{LASI}=$ L. sibirica $; \mathrm{PISI}=$ P. sibirica $; \mathrm{PISY}=P$. sylvestris .

Fig. 2. Maps showing loadings for each varimax factor in the full period (1790-1994).

Fig. 3. PC1 scores for each region. Positive PC scores represent above-average growth, and negative PC scores indicate below-average growth. The bold red lines are an 11-year lowesssmoothing of each time-series.

Fig. 4. Maps showing loadings from the five varimax factors over the early period (1790-1891).

Fig. 5. Maps showing loadings from the four varimax factors over the late period (1892-1994).

Fig. 6. Ranking of the most severe periods of reduced growth using a 3-year running average. The higher the ranking, the more severe the event (i.e. the lower the averaged PC1 component scores).

Fig. 7. Ranking of the most severe periods of reduced growth using a 5-year running average. The higher the ranking, the more severe the event (i.e. the lower the averaged PC1 component scores). 
Fig. 1

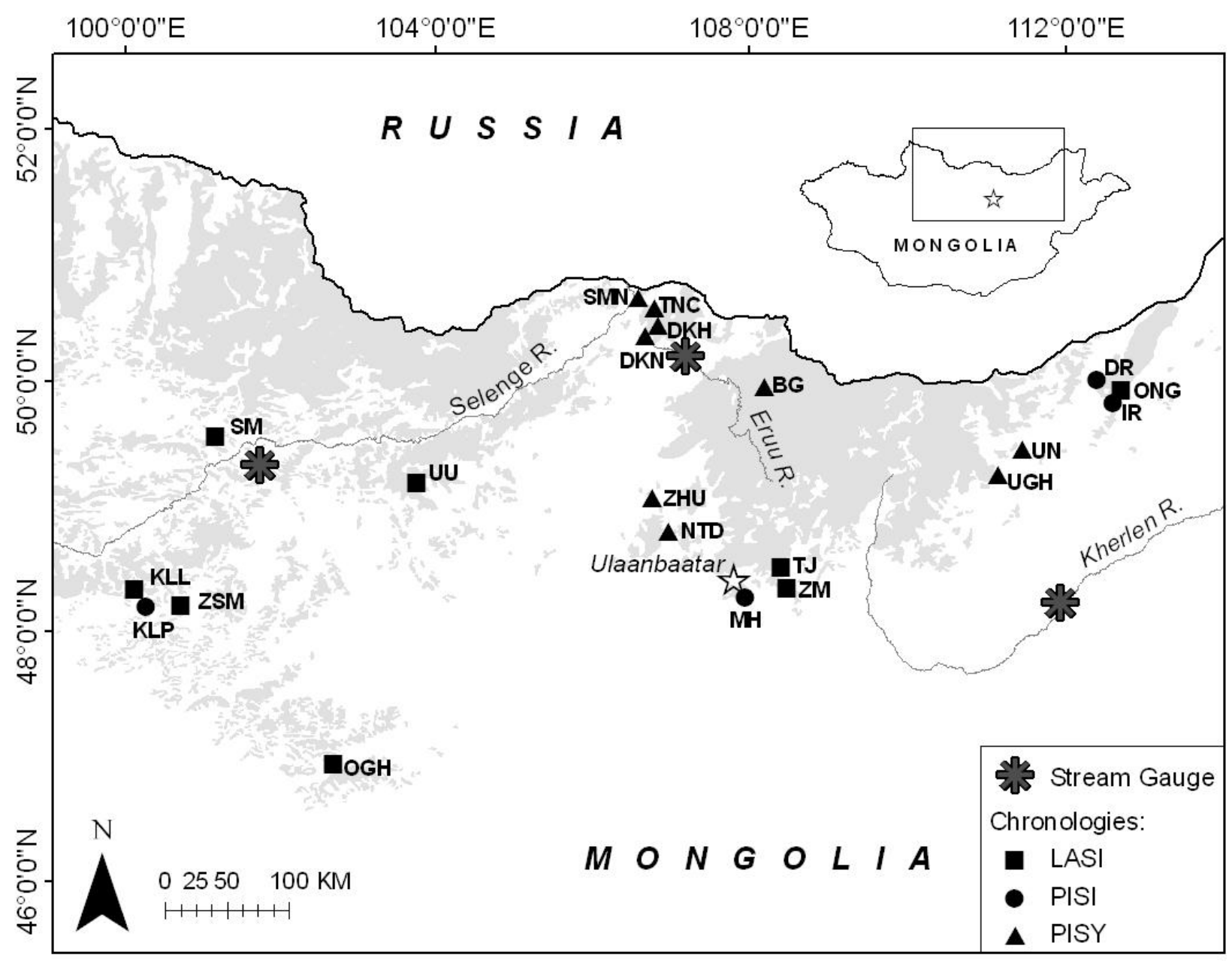


Fig. 2
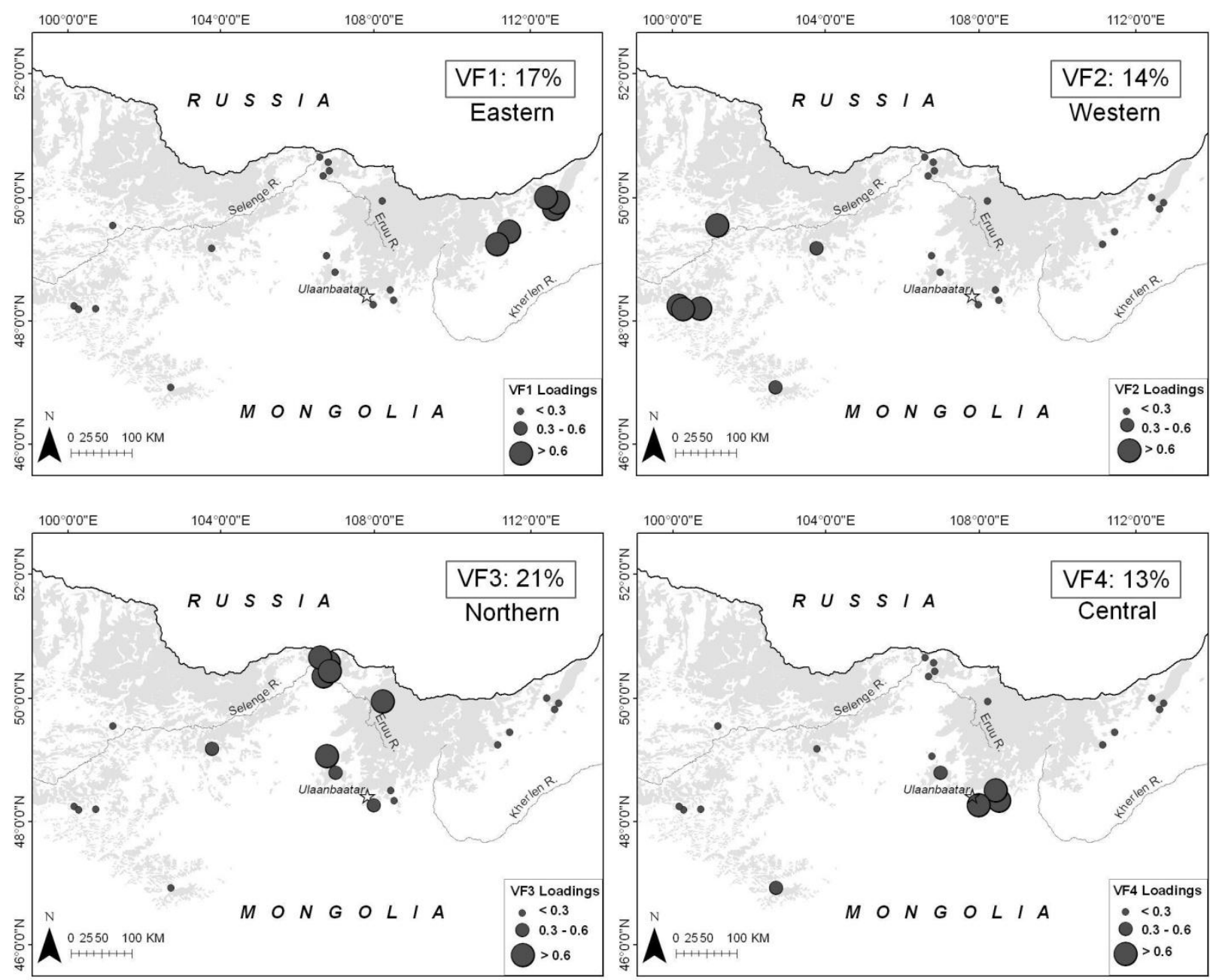
Fig. 3

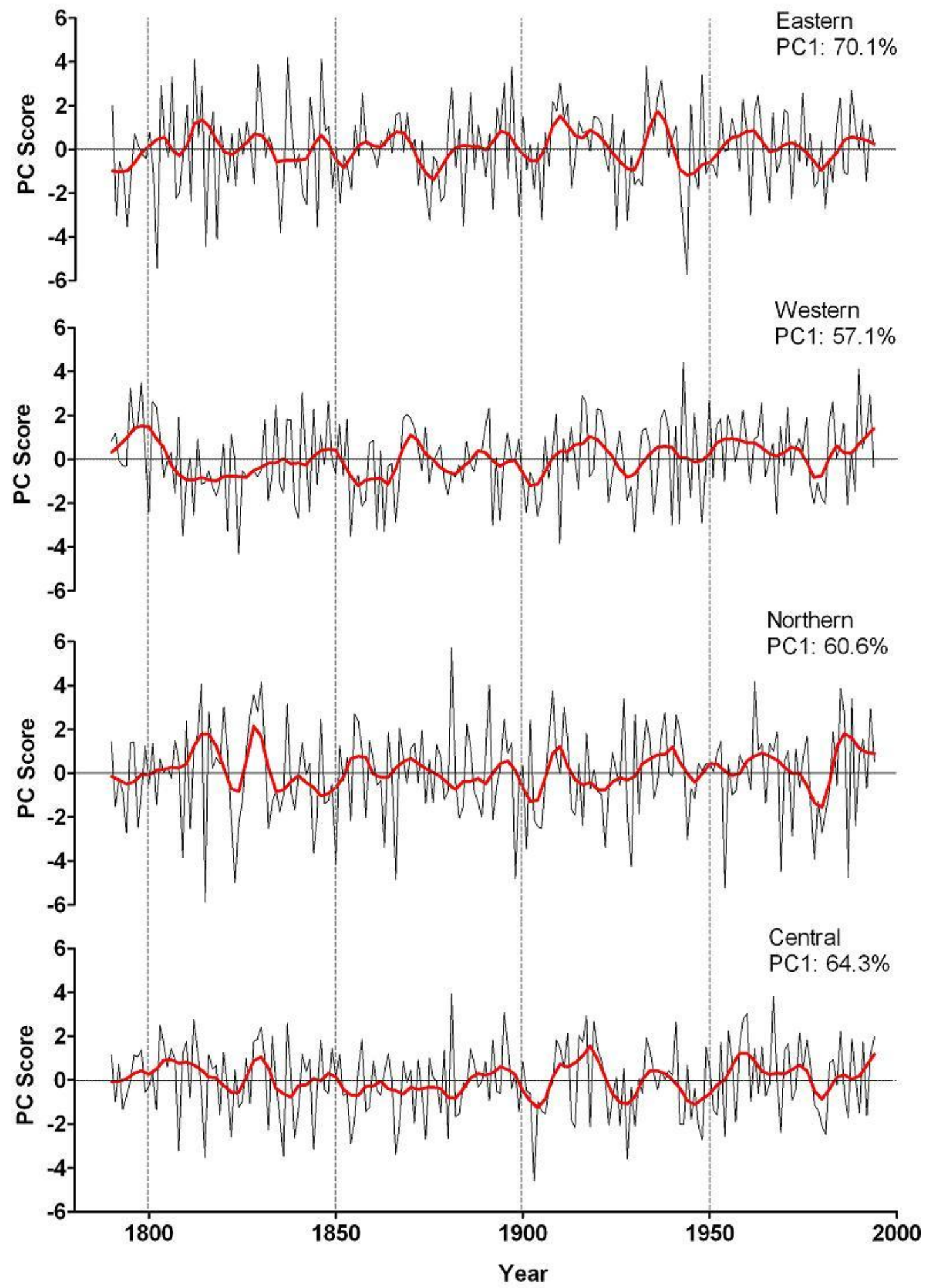


Fig. 4
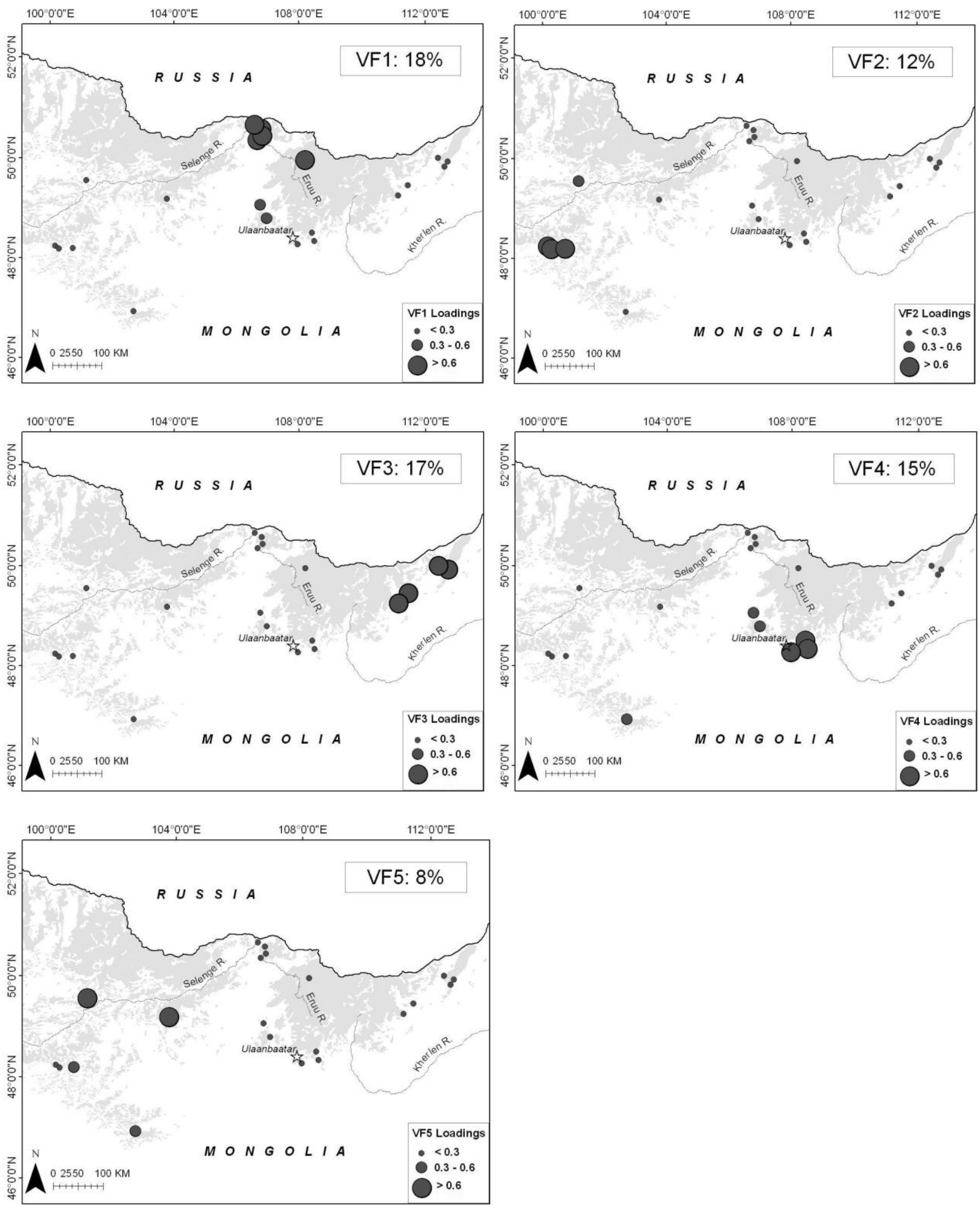
Fig. 5
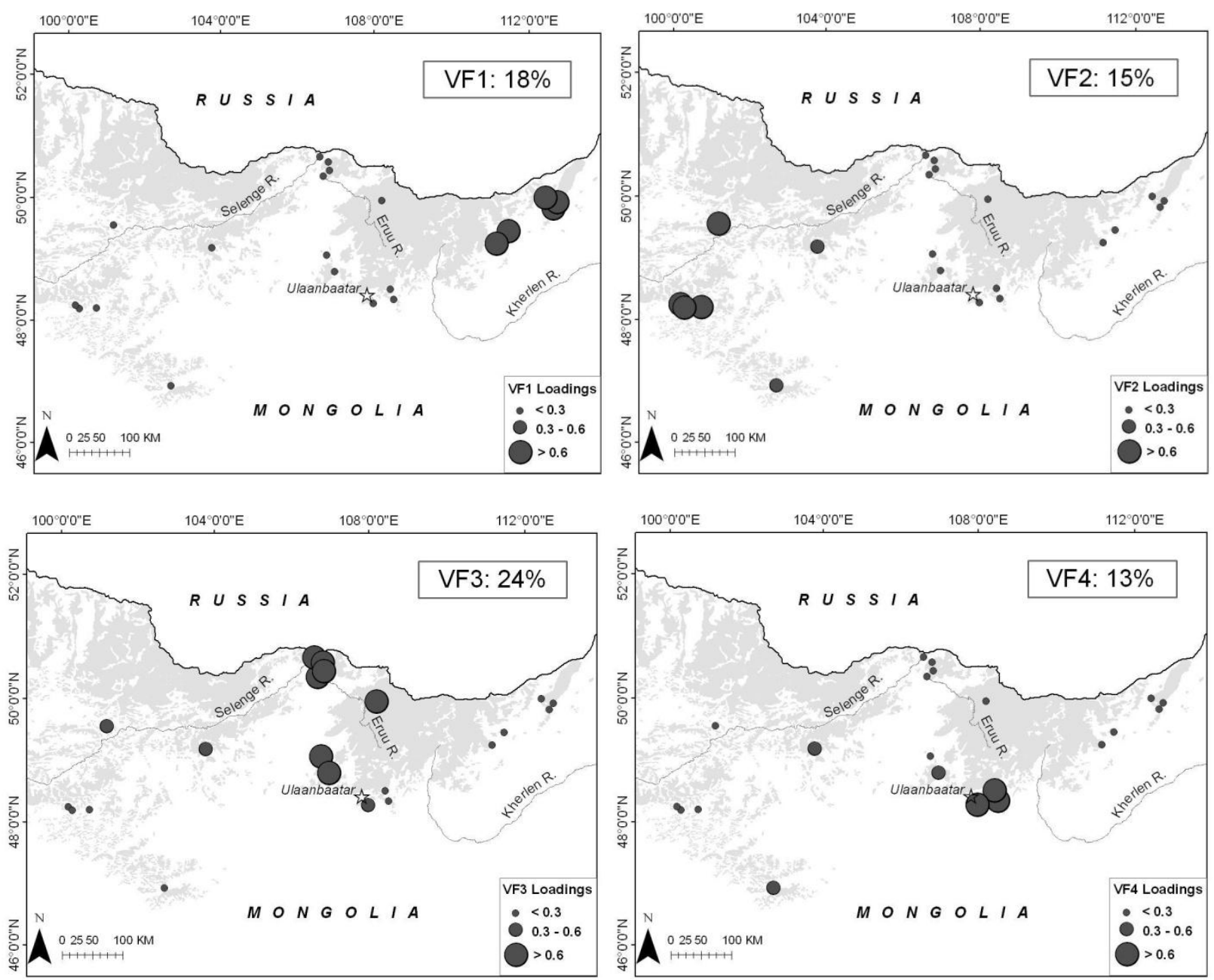
Fig. 6
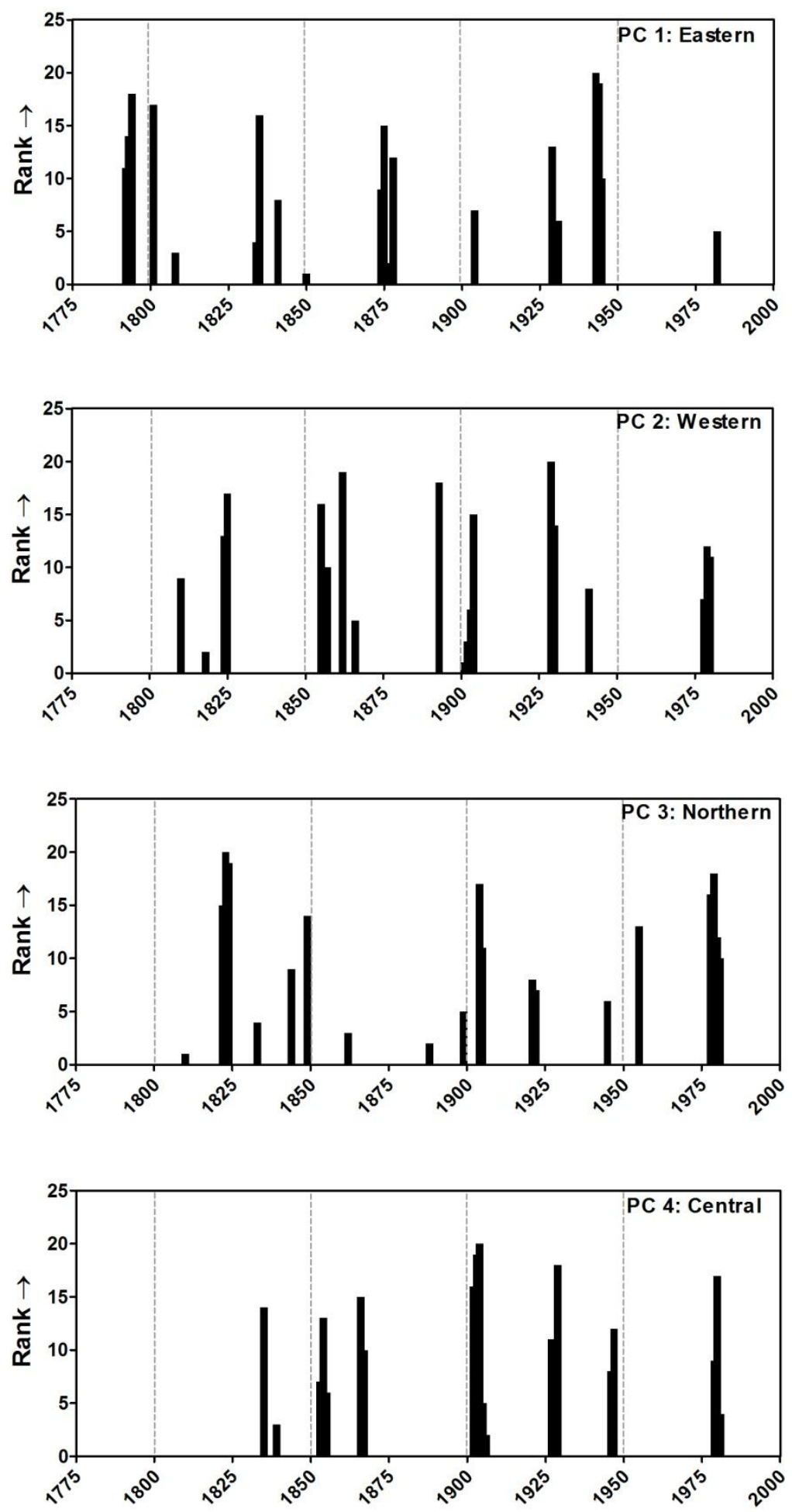
Fig. 7
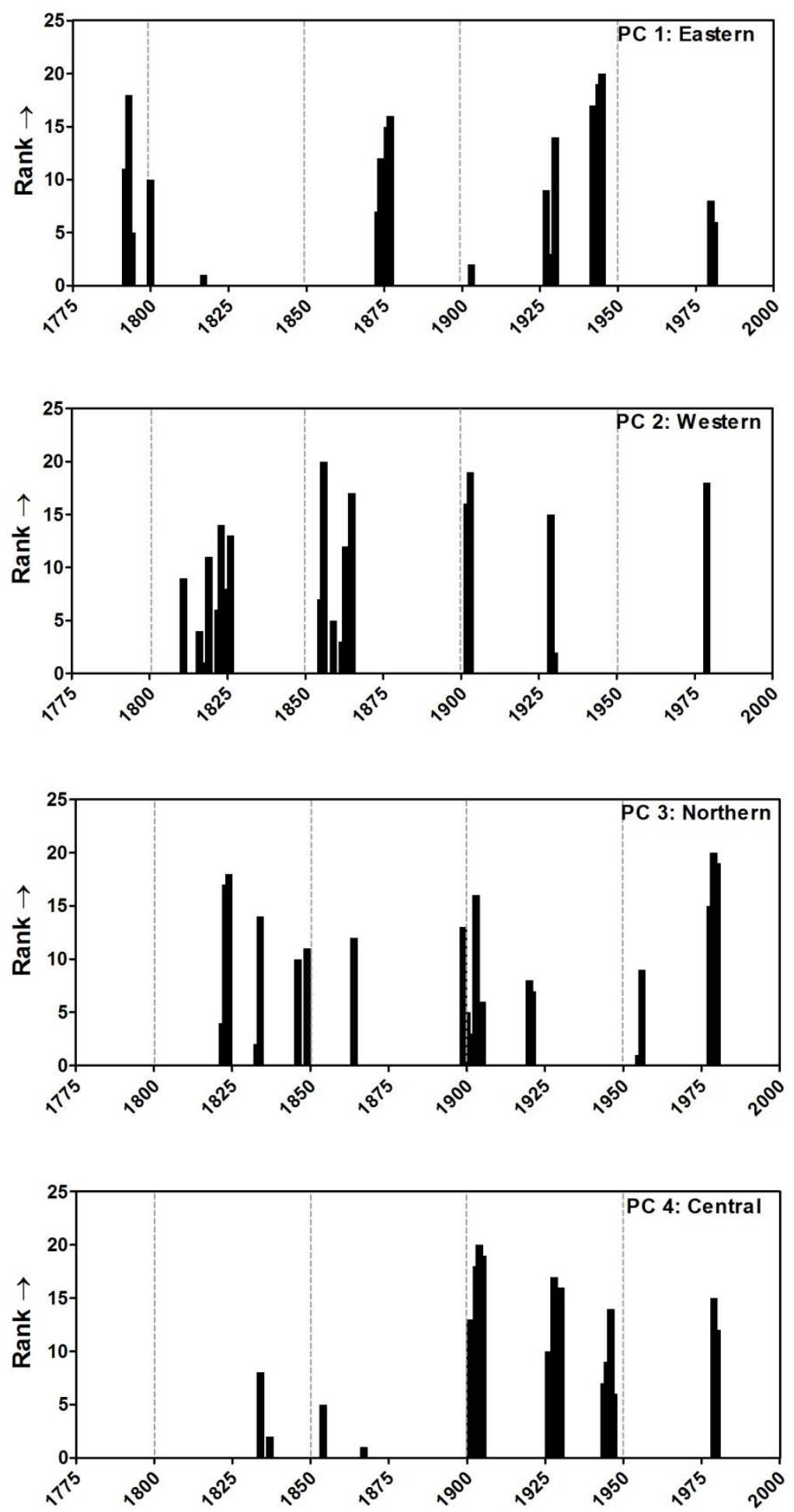


\section{Appendix}

Appendix A. Varimax factor loadings from the full period RPCA (1790-1994).

\begin{tabular}{l|l|l|l|l}
\hline Chronology & \multicolumn{1}{l}{$\boldsymbol{V F 1}$} & $\boldsymbol{V F 2}$ & $\boldsymbol{V F 3}$ \\
\hline Khorgo Lava Larch & 0.007 & $\mathbf{0 . 8 6 2}$ & 0.056 & -0.064 \\
Khorgo Lava Pine & 0.000 & $\mathbf{0 . 8 1 4}$ & 0.007 & 0.060 \\
Zuun Salaa Mod & 0.011 & $\mathbf{0 . 8 3 8}$ & 0.009 & 0.110 \\
Orkhon Gol Hurshee & 0.047 & 0.390 & -0.060 & $\mathbf{0 . 4 8 7}$ \\
Suulchyin Medee & -0.109 & $\mathbf{0 . 6 5 1}$ & 0.267 & 0.067 \\
Under Ulaan & 0.070 & $\mathbf{0 . 4 3 2}$ & 0.394 & 0.281 \\
Tujin Nars & 0.164 & -0.081 & $\mathbf{0 . 8 2 2}$ & 0.033 \\
Shaamar Mahan Nars & 0.133 & 0.141 & $\mathbf{0 . 7 7 8}$ & 0.157 \\
Dulaankhan & 0.164 & 0.063 & $\mathbf{0 . 8 5 8}$ & 0.041 \\
Delger Khan Uul & 0.037 & 0.123 & $\mathbf{0 . 7 6 5}$ & 0.034 \\
Zurkh Uul & 0.155 & 0.124 & $\mathbf{0 . 6 6 2}$ & 0.221 \\
Narstain Davaa & 0.160 & 0.138 & $\mathbf{0 . 5 5 1}$ & 0.435 \\
Bugant & 0.221 & -0.007 & $\mathbf{0 . 7 2 0}$ & 0.185 \\
Manzshir Hiid & 0.265 & 0.066 & 0.338 & $\mathbf{0 . 7 0 9}$ \\
Terelj & 0.191 & 0.052 & 0.204 & $\mathbf{0 . 8 6 8}$ \\
Zuun Mod & 0.121 & -0.012 & 0.152 & $\mathbf{0 . 8 6 9}$ \\
Uglugchiin Herem & $\mathbf{0 . 7 2 9}$ & 0.036 & 0.228 & 0.035 \\
Urgun Nars & $\mathbf{0 . 7 7 5}$ & -0.044 & 0.173 & 0.249 \\
Dadal & $\mathbf{0 . 7 9 8}$ & 0.023 & 0.140 & 0.112 \\
Inferno Ridge & $\mathbf{0 . 8 9 3}$ & -0.037 & 0.116 & 0.128 \\
Onon Gol & $\mathbf{0 . 8 5 4}$ & -0.028 & 0.119 & 0.115 \\
\hline
\end{tabular}


Appendix B. Varimax factor loadings from the late period RPCA (1892-1994).

\begin{tabular}{l|c|c|c|c}
\hline Chronology & \multicolumn{1}{l}{$\boldsymbol{V F 1}$} & $\boldsymbol{V F} 2$ & $\boldsymbol{V F 3}$ & -0.012 \\
\hline Khorgo Lava Larch & 0.042 & $\mathbf{0 . 8 8 6}$ & 0.110 & 0.059 \\
Khorgo Lava Pine & 0.081 & $\mathbf{0 . 8 3 9}$ & 0.040 & 0.132 \\
Zuun Salaa Mod & 0.089 & $\mathbf{0 . 8 8 0}$ & -0.066 & $\mathbf{0 . 5 3 0}$ \\
Orkhon Gol Hurshee & 0.085 & 0.429 & 0.312 & 0.186 \\
Suulchyin Medee & -0.229 & $\mathbf{0 . 6 0 5}$ & $\mathbf{0 . 4 8 4}$ & 0.329 \\
Under Ulaan & -0.023 & 0.339 & $\mathbf{0 . 8 3 8}$ & 0.060 \\
Tujin Nars & 0.182 & -0.063 & $\mathbf{0 . 8 4 0}$ & 0.110 \\
Shaamar Mahan Nars & 0.217 & 0.078 & $\mathbf{0 . 8 6 7}$ & 0.024 \\
Dulaankhan & 0.158 & 0.031 & $\mathbf{0 . 7 2 1}$ & 0.094 \\
Delger Khan Uul & -0.017 & 0.166 & $\mathbf{0 . 7 5 3}$ & 0.070 \\
Zurkh Uul & 0.158 & 0.086 & $\mathbf{0 . 6 4 1}$ & 0.325 \\
Narstain Davaa & 0.123 & 0.114 & $\mathbf{0 . 7 6 0}$ & 0.118 \\
Bugant & 0.270 & 0.066 & 0.395 & $\mathbf{0 . 6 5 7}$ \\
Manzshir Hiid & 0.291 & 0.053 & 0.203 & $\mathbf{0 . 8 5 0}$ \\
Terelj & 0.211 & 0.151 & 0.140 & $\mathbf{0 . 8 8 5}$ \\
Zuun Mod & 0.156 & 0.004 & 0.293 & 0.001 \\
Uglugchiin Herem & $\mathbf{0 . 7 4 8}$ & 0.144 & 0.260 & 0.268 \\
Urgun Nars & $\mathbf{0 . 7 8 3}$ & 0.092 & 0.171 & 0.081 \\
Dadal & $\mathbf{0 . 8 1 6}$ & 0.048 & 0.063 & 0.196 \\
Inferno Ridge & $\mathbf{0 . 8 8 2}$ & -0.081 & 0.097 & 0.163 \\
Onon Gol & $\mathbf{0 . 8 6 8}$ & -0.058 & &
\end{tabular}


Appendix C. Varimax factor loadings from the early period RPCA (1790-1891).

\begin{tabular}{|c|c|c|c|c|c|}
\hline Chronology & VF1 & VF2 & VF3 & VF4 & VF5 \\
\hline Khorgo Lava Larch & 0.030 & 0.879 & -0.038 & -0.088 & 0.125 \\
\hline Khorgo Lava Pine & 0.002 & 0.843 & -0.091 & 0.080 & 0.058 \\
\hline Zuun Salaa Mod & -0.005 & 0.709 & -0.112 & 0.090 & 0.327 \\
\hline Orkhon Gol Hurshee & -0.073 & 0.190 & -0.016 & 0.419 & 0.322 \\
\hline Suulchyin Medee & 0.185 & 0.411 & -0.025 & -0.034 & 0.682 \\
\hline Under Ulaan & 0.243 & 0.168 & 0.137 & 0.211 & 0.771 \\
\hline Tujin Nars & 0.821 & -0.130 & 0.140 & 0.034 & 0.011 \\
\hline Shaamar Mahan Nars & 0.728 & 0.103 & 0.088 & 0.224 & 0.274 \\
\hline Dulaankhan & 0.845 & 0.034 & 0.159 & 0.103 & 0.141 \\
\hline Delger Khan Uul & 0.807 & 0.046 & 0.073 & 0.035 & 0.117 \\
\hline Zurkh Uul & 0.533 & 0.253 & 0.165 & 0.437 & -0.110 \\
\hline Narstain Davaa & 0.419 & 0.248 & 0.214 & 0.591 & -0.074 \\
\hline Bugant & 0.668 & -0.069 & 0.177 & 0.280 & -0.026 \\
\hline Manzshir Hiid & 0.252 & 0.118 & 0.242 & 0.793 & -0.083 \\
\hline Terelj & 0.161 & -0.102 & 0.162 & 0.880 & 0.079 \\
\hline Zuun Mod & 0.138 & -0.181 & 0.076 & 0.812 & 0.228 \\
\hline Uglugchiin Herem & 0.212 & 0.028 & 0.692 & 0.066 & -0.227 \\
\hline Urgun Nars & 0.102 & -0.146 & 0.759 & 0.212 & -0.150 \\
\hline Dadal & 0.084 & -0.064 & 0.789 & 0.139 & 0.188 \\
\hline Inferno Ridge & 0.146 & -0.030 & 0.905 & 0.093 & 0.110 \\
\hline Onon Gol & 0.132 & -0.064 & 0.832 & 0.078 & 0.144 \\
\hline
\end{tabular}


Appendix D. Varimax factor loadings from the reduced dataset RPCA.

\begin{tabular}{c|c|c|c}
\hline Cluster Assignment & \multicolumn{1}{c}{ VF1 } & VF2 & VF3 \\
\hline 1 & -0.08 & 0.17 & $\mathbf{0 . 7 5}$ \\
2 & 0.23 & -0.09 & $\mathbf{0 . 7 8}$ \\
3 & -0.22 & 0.51 & $\mathbf{0 . 5 8}$ \\
4 & 0.03 & $\mathbf{0 . 6 5}$ & 0.44 \\
5 & 0.29 & $\mathbf{0 . 8 0}$ & -0.05 \\
6 & 0.32 & $\mathbf{0 . 7 6}$ & 0.04 \\
7 & $\mathbf{0 . 5 0}$ & 0.40 & 0.28 \\
8 & $\mathbf{0 . 7 9}$ & 0.14 & -0.03 \\
9 & $\mathbf{0 . 8 7}$ & 0.14 & 0.00 \\
10 & $\mathbf{0 . 8 2}$ & 0.13 & 0.01 \\
\hline
\end{tabular}


Chapter 2: The Spatiotemporal Expression of Droughts and Pluvials across North-central Mongolia

\author{
Caroline Leland ${ }_{1}^{*}$
}

1. Department of Geology and Geography West Virginia University, P.O. Box 6300,

Morgantown, West Virginia 26506, USA. *Corresponding author: carolineleland@ gmail.com 


\begin{abstract}
Mongolia is characterized by climatic extremes, particularly drought, and there is uncertainty in how global climate change could influence local moisture availability. Instrumental records in Mongolia are limited in time and space and do not provide a sufficient understanding of how recent climatic change compares to variability in the past. Therefore, treering networks are used to infer spatial and temporal variability in hydroclimate. Here, we evaluate individual chronologies, and tree-growth anomaly regions identified within a tree-ring network, to assess the spatiotemporal characteristics of major drought and pluvial events in north-central Mongolia. We take particular interest in the severe drought event lasting from 1999-2002. Results here suggest that many of the regions identified within the network share similar drought and pluvial events, though the Eastern and Western extremes of the network are especially different from one another. The Western region, in particular, is the least correlated with all other regions. All regions show similar temporal patterns in hydroclimate, particularly from 1950-1994, which was a notably wetter period relative to the previous $\sim 150$ years. From a spatial perspective, some drought and pluvial events affect the entire network (e.g. 1920s droughts), whereas others appear to be localized (e.g. 1940s droughts). Spatial maps of major droughts and pluvials, including the 1999-2002 droughts, illustrate variability within and between regions. This study highlights the extent of temporal and spatial variability of hydroclimate across north-central Mongolia, which could be valuable for future water resource management efforts.
\end{abstract}

Keywords: tree rings, droughts, pluvials, network, Mongolia 


\section{Introduction}

Drought is a recurring phenomenon across the Mongolian landscape, and there is great concern over the potential influence of global climate change on the intensity and frequency of drought events (Angerer 2008). The damaging impacts of annual and multiannual droughts reverberate through Mongolia's culture and economy. The agricultural and livestock sectors of the economy, which accounted for greater than a third of the GDP in 2000 (Siurua and Swift 2002), are especially vulnerable to moisture deficits. A combination of summer droughts and harsh winter conditions ('dzud') affected roughly 50-70\% of Mongolia from 1999-2002 (Batima et al. 2005) and resulted in a loss of 35\% of the nation's livestock (Angerer et al. 2008). In the western and central mountains and the Gobi Desert, more than half of the local herds perished (Siurua and Swift 2002). The recent explosion of livestock numbers, and the degradation of pasture lands due to overgrazing, increases the vulnerability of Mongolians to extreme climatic events (Borgford-Parnell 2009). Therefore, the characterization of past moisture availability, and its relationship to recent climatic trends, might be instrumental in understanding the risk of climatic extremes on Mongolian livelihoods.

Studies of precipitation trends over the instrumental period (Batima et al. 2005, Endo et al. 2006, Li et al. 2009), and projections of precipitation linked to global climate change (Sato et al. 2007) indicate that hydroclimatic variability is highly local across Mongolia. In studying drought trends from 1951-2005 using a gridded Palmer's Drought Severity Index (PDSI) network, Li et al. (2009) identified an overall drying trend in far-eastern Mongolia, whereas there was no significant moisture trend in western and central Mongolia. Further, Batima et al. (2005) highlight local variability across Mongolia by displaying precipitation trends from 1970-2001 using individual instrumental stations. Some parts of north-central Mongolia experienced 
precipitation decreases, and parts of western and eastern Mongolia incurred increases. Interestingly, neighboring stations sometimes show opposite trends. The spatial complexity of hydroclimate in Mongolia can be attributed to several factors. On a broad spatial scale, much of Mongolia's climate is influenced by prevailing westerly winds, and potential influences from the Asian monsoon in summer months (Sato et al. 2007). However, complex topography mediates spatial precipitation patterns on regional or local scales (Sato et al. 2004, Kim et al. 2011). An understanding of local climatic variability may be more relevant and important to Mongolians than broader-scale assessments (Marin 2010).

The full extent of hydroclimatic variability in Mongolia is difficult to capture with instrumental records considering the limited spatial coverage of meteorological stations. Further, these climate records rarely provide data prior to 1940. In order to account for these shortcomings, tree-ring records have been used to infer hydroclimatic variability several centuries into the past in several parts of Mongolia (Pederson et al. 2001, Davi et al. 2006, Davi et al. 2009, 2010). These reconstructions also demonstrate strong regional variability in hydroclimate (e.g. western Mongolia has shown a significant wetting trend over the $20^{\text {th }}$ century (Davi et al. 2009), which is not evident in central (Davi et al. 2006) nor eastern Mongolia (Pederson et al. 2001)). Additionally, tree-ring networks have been a valuable means of evaluating spatial and temporal characteristics of tree-growth anomalies (i.e. tree-growth patterns) and related climatic patterns (e.g. Meko et al. 1993, Watson and Luckman 2001). An analysis of tree-growth anomalies over a chronology network in north-central Mongolia suggested that there are four distinct sub-regions which likely correspond to distinct hydroclimatic regions (Chapter One). 
The purpose of this paper is to evaluate spatiotemporal characteristics of droughts and pluvials across a network of 21 tree-ring chronologies in north-central Mongolia. Four subregions from Chapter One, and individual tree-ring chronologies, are evaluated to discern the nature of hydroclimatic variability across north-central Mongolia on different spatial scales. First, we quantify regional droughts and pluvials across the chronology network. Then, we: 1) investigate the spatial expression of the most notable droughts and pluvials on the chronologyscale, and 2) assess the relative strength of droughts and pluvials over time. We specifically examine the extended drought event from 1999-2002, though this analysis was not possible across the full network of chronologies.

\section{Materials and Methods}

\subsection{Tree-ring Data}

This study incorporates a network of 21 tree-ring chronologies from north-central Mongolia ranging from $46^{\circ} 47^{\prime}-50^{\circ} 09^{\prime} \mathrm{N}$ and $99^{\circ} 52^{\prime}-111^{\circ} 41 \mathrm{E}$ (Fig. 1). The network consists of three species, $P$. sylvestris, $P$. sibirica, and L. sibirica (Table 1). Of the 21 chronologies, 11 were originally developed by those involved with the Mongolian American Tree-ring Project (MATRIP), a collaboration between scientists from Lamont-Doherty Earth Observatory and Mongolia. The remaining 10 chronologies were developed from tree-ring data collected in the summers of 2009 and 2010. Chronologies were collected from sites that appeared moisture-limited. The sites typically had steep slopes and rocky or well-drained substrate. Due to the patchiness of forest cover across the study region, the spatial distribution of chronologies is highly uneven. The species distributions are also irregular, where the western part of the network consists mostly of L. sibirica, and the eastern and north-central part of the network are largely dominated by Pinus spp. 
To make certain that differences between chronologies were not an artifact of standardization, the MATRIP tree-ring data were re-standardized to complement the methods used here. After ensuring all tree-ring data were successfully cross-dated (Stokes and Smiley 1968) with the program Cofecha (Holmes 1983), the software program ARSTAN (Cook 1985) was used for standardization and chronology development. First, the heteroscedastic variance was removed in each individual series with a data-adaptive power transformation (Cook and Peters 1997), and then each series was detrended with a linear or negative exponential curve to remove allometric growth trends. Some series, particularly those from closed-canopy forests, displayed suppression and release trends likely resulting from endogenous stand dynamics (Lorimer and Frelich 1989). Those series were detrended again using a conservative Friedman supersmoother curve ( $\alpha$ level between 6 and 9 ) to further reduce the effects of non-climatic trends in the ring widths (Buckley et al. 2010, Friedman 1984) while preserving low-frequency trends (Pederson et al. 2004). Due to different serial autocorrelation inherent in the three species used here, we used only residual chronologies in this study. First, low-order autocorrelation was removed in each series. Variance was stabilized using either the Keith Briffa or one-third spline method, and finally, the individual series were averaged together with a biweight robust mean to produce the final residual chronology (Cook 1985).

Following chronology development, tree-growth anomaly regions were identified across the full chronology network with a varimax-rotated principal components analysis (RPCA) (e.g. Brubaker 1980, Meko et al. 1993). Refer to the results of Chapter One. In summary, the RPCA was applied to all 21 residual chronologies, and four regions (i.e. components) were established - the Eastern, Western, Northern and Central regions. Each chronology was assigned to a treegrowth anomaly region (refer to Fig. 1 for region memberships). A time-series of PC scores was 
produced for each region for the common period of 1790-1994 (Fig. 2). An analysis comparing regional PC scores and instrumental data suggests that annual variability in PC scores likely reflects hydroclimatic variability, where smaller (more negative) PC scores indicate smaller growth years (i.e. drier years), and larger (more positive) PC scores indicate larger growth years

(i.e. wetter years). Therefore, we consider the time-series of PC scores to be a proxy for past hydroclimatic variability. Both the regional PC scores, and the individual tree-ring chronologies, which are considered to reflect site-specific moisture variability, are used in the following analyses.

\subsection{Identifying Drought and Pluvial Events}

We quantified drought and pluvial events for each region in the network using a method proposed by Biondi et al. $(2002,2005)$. Here, this method is referred to as runs analysis (Salas 1980), which has been described in several dendroclimatological studies (Pederson et al. 2006, Gray et al. 2004, Gray et al. 2011). For each regional time-series, we defined drought and pluvial events as two or more consecutive years below or above the median PC score, respectively. The events were then expressed in terms of their duration, magnitude, and intensity. The duration refers to the number of consecutive years below (or above) the median PC score; the magnitude is the 'area under the curve', or the total sum of annual values for each drought or pluvial event; and the intensity is calculated as the magnitude divided by the duration. Following the method outlined by Gray et al. (2011), we calculated a score for each drought and pluvial event by adding together the magnitude and intensity values. The higher the score, the stronger the drought or pluvial event. Then, we ranked the scores separately for the drought and pluvial events to gauge their relative severity. We also examined variability in each region with an 11year lowess smoothing curve for each time series (Fig. 2). 


\subsection{Quantifying and Mapping Spatiotemporal Patterns of Droughts and Pluvials}

Following the identification and quantification of drought and pluvial events in all four regions, we considered the cumulative importance of these hydroclimatic events over time. We split the common period into four 50-year periods $(1800-1849,1850-1899,1900-1949,1950$ 1994) and summed the scores of each drought and pluvial event that occurred in each period. In the case where an event overlapped two periods, the score associated with that event was included in the period of time in which it began. Results of this analysis are interpreted such that the higher cumulative drought (pluvial) score, the more important droughts (pluvials) were for characterizing the hydroclimate of that particular period of time. In other words, this analysis might be used to gauge the relative severity of droughts versus pluvials in each $\sim 50$-year period.

Another way to examine temporal variability in hydroclimate (i.e. PC scores) is through the use of violin plots. Violin plots combine box plots and density estimates to graphically display the 'structure' of a dataset, therefore, they provide more information on the distribution of a dataset than box plots alone (Hintze and Nelson 1998). Here, we computed violin plots for $\sim 50$-year segments for each region separately.

After considering the temporal variability of droughts and pluvials, we determined the spatial expression of major drought and pluvial events across the entire network. The top-five drought and pluvial events in each of the four regions were analyzed on the chronology-scale. We calculated z-scores based on the index values for each chronology from 1790-1994. For each major drought/pluvial event, the annual growth percentiles (inferred from the z-scores) of each chronology were averaged over the entire duration of the event to produce a single value. Then, we mapped the averaged percentile value for each chronology across the network using ArcGIS Ver. 9.2.; we mapped only the most important (i.e. highest scoring) drought and pluvial 
event for each region. To quantitatively evaluate the spatial extent of major drought and pluvial events, we listed the percentage of chronologies with an averaged growth percentile $<25$ for drought events, and $>75$ for pluvial events.

We conducted the analysis of the 1999-2002 drought event only for the Northern region because all chronologies within the region recorded the full event (i.e. all chronologies were collected after 2002). Other regions consisted of chronologies that were collected prior to 2002. A new, single time-series of PC scores was created for the Northern region based on the common period of all chronologies located within the region (1790-2008). Following the methods described above, we quantified droughts and pluvials in the Northern region from 1790-2008 to determine the ranking of the 1999-2002 droughts relative to droughts in previous decades. In order to capture the spatial characteristics of the recent droughts, z-scores were computed for all chronologies in the Northern region from 1790-2008; after this, the corresponding annual growth percentiles for each chronology were mapped for select years. For this analysis, we chose to map only single years, as opposed to $2+$ year drought events, to capture the recent, annual variability in hydroclimate across the Northern region.

\section{Results}

\subsection{The Four Regions}

The top-five drought and pluvial events for each region are listed in Tables 2 and 3, respectively, and specifics on their calculation are provided (Appendix A and B). Some of the drought/pluvial events are common among more than one region. For example, the extended drought in the late-1920s was listed as one of the top-five events in the Eastern, Northern and Central regions. The late-1920s drought was also evident in the Western region (ranked eighth). The Eastern, Northern and Central regions also share the late-1820s pluvial as a top-five event 
(Table 2). In contrast, the Western region was experiencing a 7-year long drought from 1824 to 1830. The Eastern and Western regions do not share any of the top-five drought or pluvial events. Overall, the Eastern, Northern, and Central regions display similar longer-term variability in hydroclimate, with the extended droughts of the early 1900s and the 1940s, as well as the pluvials of the 1820s and 1910s (Fig. 2). Conversely, the Western region has some periods of severe droughts (early 1800s and 1850s-1860s) that are not evident in the other regions. The Western region is the least correlated with all other regions from 1790-1994. The Eastern, Northern and Central regions correlate the highest with one another, with the Northern and Central regions having the highest correlation of all comparisons $(r=0.439, \mathrm{p}<0.05)$ (Table 4).

Drought and pluvial severity varies considerably over $\sim 50$-year periods across the four tree-growth anomaly regions (Tables 5 and 6, respectively). All regions display a marked decrease in the total drought score from 1950-1994, particularly in the Western region. The Eastern region, however, had a severe drought from 1949-1952 that was only considered in the 1900-1949 period. If this drought had been considered in the 1950-1994 period, then the reduction in cumulative drought score during that time would have not been as evident. The 1800-1849 and 1900-1949 periods generally show a larger cumulative drought score in all regions. The cumulative pluvial scores also display distinct patterns. For example, the 1950-1994 period had a relatively high cumulative pluvial score for all regions, whereas the 1850-1899 period generally had a low cumulative pluvial score for the Western, Eastern, and Central regions.

Violin plots were used to supplement the results of cumulative scores for drought and pluvial events over time (Fig. 3). Specifically, the violin plots highlight the wetter conditions during the 1950-1994 period, which is evident by an increased median in all regions except for 
the Eastern region. It should be noted, however, that the means were not significantly different between the 1900-1949 and 1950-1994 periods for any of the regions at the $\mathrm{p} \leq 0.05$ significance level (Appendix C). In fact, there were no significant differences between the means of any temporal periods in any of the regions ( $\mathrm{p} \leq 0.05$ significance level) (Appendix D). There is a reduced variability in PC scores from 1850-1899 in all regions, however, there are a few more extreme (wet and dry) years that are visible during this time in the Northern and Central regions. All regions generally show a more even distribution of PC scores around the mean from 19001949, with only the Eastern region displaying some outlier values; these values coincide with the large, negative spike in PC scores in the 1940s (Fig. 2).

After assessing temporal characteristics of droughts and pluvials over the four regions, we evaluated the spatial expression of major drought and pluvial events across all of the chronologies in the network. The extent of the top-five major drought and pluvial events for each region can be inferred from Tables 2 and 3. Figures 4 and 5 show the top-scoring drought and pluvial event from each region as mapped on the chronology-scale. In terms of the top-scoring drought/pluvial event for each region, the Western and Northern regions had ties in the scoring method (Appendix B). For the Western region, we displayed only the results from the 1916-1917 pluvial event; the 1990-1993 event showed similar results. In terms of the Northern region, we displayed only the 1985-1986 pluvial event; the 1826-1831 pluvial event in the Northern region, which had the same final score, is generally reflected by the $1829-1830$ pluvial event associated with the Eastern region (Fig. 5).

Maps of top-scoring drought and pluvial events indicate spatial variability across the chronology network. Maps of the highest scoring drought events for the Northern and Central regions demonstrate low averaged growth percentiles across the entire network, whereas the 
drought events associated with the Eastern and Western regions (1942-1944 and 1854-1858, respectively) show inter-regional differences (Fig. 4). Chronologies in the Eastern region have low growth percentiles from 1942-1944, whereas the chronologies in the Western region have relatively high growth percentiles. For the 1942-1944 Eastern drought, only 33 percent of all chronologies across the network had an averaged growth percentile less than 25 (Table 2). During the 1854-1858 drought of the Western Region, many chronologies in the Northern Region and Eastern region (UN and UGH) display high growth percentiles; only 24 percent of all chronologies had an averaged growth percentile less than 25 (Table 2). Conversely, some droughts were spatially expansive, such as the 1928-1929 drought in which 76 percent of the chronologies had an averaged growth percentile less than 25 percent (Table 2). Though some of the drought maps indicate a regionalization of lower averaged growth percentiles, all of the mapped pluvials (Fig. 5) generally show higher averaged growth percentiles across the entire network (i.e. no chronologies display a growth percentile $<25$ during these events, with the exception of SM during the 1829-1830 pluvial). It is important to note, however, that not all important pluvials were spatially expansive. The 1943-1944 pluvial in the Western Region (Table 3) was highly localized, and as noted above, was a considerable droughty period in the Eastern Region (Fig. 4). Further, Table 3 suggests that many other pluvials were regionalized, particularly those occurring in the Eastern and Western regions. As an example, only 24 percent of the chronologies in the network displayed an averaged growth percentile greater than 75 percent during the 1933-1938 pluvial of the Eastern region.

\subsection{The 1999-2002 Drought Event}

Quantification of drought and pluvial events from 1790-2008 in the Northern region of the network indicated that there was a severe drought lasting from 2000-2003 (results not 
shown). Interestingly, the year 1999 was not included as part of this drought because the PC score value of that year for the entire Northern Region was above the long-term median. The 2000-2003 drought received a cumulative score of 68 , which was ranked as the $12^{\text {th }}$ most severe $(2+$ year) drought for the full common period. The notable droughts of the $1790 \mathrm{~s}, 1820 \mathrm{~s}$, early 1900s, and mid-1940s ranked higher than the drought event of the early 2000s.

In mapping the growth percentiles for select years in the 1990s and 2000s, the spatial patterns of recent droughts emerged (Fig. 6). The year 1995 was a spatially expansive wet year in which all chronologies had an annual growth value greater than the $75^{\text {th }}$ percentile. In stark contrast to 1995, the year 1996 was characterized as a drought across the entire network where all chronologies had a growth value less than the $25^{\text {th }}$ percentile (except for DKH). Chronology growth percentiles for the years 1997 and 1998 were much more spatially variable than the prior two years. The years 1997 and 1998 were droughty for the ZHU and NTD chronologies in the southern part of the region, whereas the far northern chronologies (SMN, TNC, DKH, and DKN) had much higher growth percentiles. An inverse pattern occurred in 1999, where the far northern part of the region displayed lower growth percentiles relative to the southern part of the region.

The 2000-2003 drought period identified for the Northern region was characterized by high spatial variability in annual growth percentiles (only the 2000-2002 maps are shown in Fig. 6). In particular, the year 2000 was characterized by lower growth percentiles for the southern part of the region and higher growth percentiles for the northern part of the region (except for TNC). Chronologies located in the southern part of the Northern region (ZHU and NTD) consistently showed low growth percentiles during the entire drought period. Additionally, ZHU and NTD typically had the same growth response from year to year. Interestingly, chronologies 
in the far north, despite their close proximity, often had contrasting growth percentiles in the same year.

\section{Discussion}

\subsection{Regional Variability}

In comparing the top-five drought and pluvial events for each region in the network, it is apparent that many of the regions share the same extreme, hydroclimatic events. The droughts during the late-1920s, which strongly affected nearly all of the regions and were evident in hydroclimatic reconstructions in eastern and central Mongolia (Pederson et al. 2001, Davi et al. 2006), were also notable in northern and central China (Liang et al. 2003, Li et al. 2007, Gou et al. 2007, Qian et al. 2007). According to a drought reconstruction in north-central China, the droughts of the 1920s were unparalleled, and the most severe since 1788 (Li et al. 2007). In contrast, other droughts and pluvials identified in this study were more region-specific within Mongolia. The 1940s drought events were important for the Eastern, Central and Northern regions, whereas the Western region experienced one of the top-ranked pluvials from 1943-1944. Similarly, the pluvials of the late-1820s common among the Eastern, Northern, and Central regions were in opposition to the Western region. These results, among others, indicated the stark differences between the Western region and other regions. Most notably, the Eastern and Western regions did not have any major drought or pluvial events in common, and the regional PC scores were not significantly correlated with one another. Several studies have emphasized different precipitation trends and patterns between the Khangai and Khentii mountain ranges (Sato et al. 2004, Kim et al. 2011), which separate the Western region (in the Khangai mountains) from the Eastern region (on the leeward side of the Khentii mountains). Therefore, it 
is expected that they have differing hydroclimatic patterns through time, particularly in terms of major drought and pluvial events.

In addition to spatial variability, the temporal analyses highlight the high degree of hydroclimatic variability across all regions through time. Although the temporal analyses and violin plots were conducted on arbitrary $\sim 50$-year periods, the general results support the trends visible on the time series of each region (Fig. 2). Temporal differences in hydroclimatic variability were evident in the 1850-1899 period of analysis, in which the Western and Eastern regions displayed markedly lower variability relative to other periods of time. The Northern and Central regions have more extreme years from 1850-1899, which likely reflects the higher cumulative drought and pluvial scores that were calculated for those regions during that period. In others periods of analyses, all regions showed similar trends in cumulative drought and pluvial scores. The large cumulative drought scores from 1900-1949 in all regions likely corresponds to the severe droughts of the late-1920s that influenced the entire network, and the 1940s droughts of the Eastern, Northern, and Central regions. Additionally, all regions displayed moister conditions during the 1950-1994 period, with a drastic decrease in the cumulative drought score and a concomitant increase in the cumulative pluvial score. Similar wetting trends during the mid-to-late $20^{\text {th }}$ century have been identified to a greater degree in far-western Mongolia (Davi et al. 2009) and parts of China (Shao et al. 2005, Gou et al. 2007). In testing for significant differences between the means of the various periods of time, however, the wet period of 19501994 was not particularly anomalous in any region (Appendix C). Interestingly, Li et al. (2009) observed that eastern Mongolia has been experiencing a drying trend since the 1950s, which was particularly evident beginning in the early 1990s. Though our analyses do not suggest drier conditions in any of the identified regions, the wetting trend that we identified in our analyses 
from 1950-1994 could have been significantly different if we factored in the droughts of the late 1990s and early $21^{\text {st }}$ century.

\subsection{Spatial Characteristics of Major Drought and Pluvial Events}

Though we mapped and analyzed only select drought and pluvial events, our analyses reflect the importance of inter-regional and intra-regional variability in relative growth, and likely climate, across the network. As emphasized by Batima et al. (2005) and Sato et al. (2007), hydroclimate is a highly local phenomenon in Mongolia, and it could vary to a great degree between regions. Similarly, Sternberg et al. (2010) observed drought episodes across several sites in southern Mongolia, and noted that the intensity and duration of drought events were a result of local climate anomalies, and varied significantly across the study area. This variability could be attributed to the interaction of topography, radiation balances, and synoptic-scale disturbances in generating local convective systems (Zhang and Lin 1992, Sato et al. 2007). Our results have also illustrated the complexity of major climatic events (i.e. droughts and pluvials) from a spatial perspective.

Inter-regional variability was most evident in our maps of top-scoring drought events, which illustrated strong differences between the Eastern and Western regions of the network. Though we mapped only a few, select drought events, this pattern is also evident in correlation analyses (Table 4) as well as the tables of shared hydroclimatic events (Tables 2 and 3). All of the mapped pluvials appeared to affect the full network, however, we found that some historical pluvials were localized as well. For example, Davi et al. (2006) noted that the most pronounced regional difference between the Selenge and Kherlen (Pederson et al. 2001) streamflow reconstructions occurred during the late 1700s when central Mongolia was much wetter than 
eastern Mongolia. Our analyses, which used many of the same chronologies as the tree-ring reconstructions, supports this finding - only $24 \%$ of the chronologies in the full network (all from the Western region, in addition to SMN) strongly experienced the 1795-1799 pluvial event (Table 3).

In general, the major drought and pluvial events associated with Northern and Central regions appeared to affect a larger relative number of chronologies in comparison to the droughts/pluvials of the Eastern and Western regions. This is evident in the spatial maps, in which the top-scoring drought and pluvial events for the Northern and Central regions mostly spanned the entire network. Tables 2 and 3 also supported this trend, in which some of the largest drought and pluvial events (e.g. 1928-1929 and 1978-1981) were the top-scoring events for the Northern and Central regions. Due to their central location, it is not particularly surprising that drought and pluvial events associated with these regions would also affect other regions within the network. However, this trend is likely not always the case; it appears as though the Northern and Central regions could have periods of unique hydroclimatic variability (refer to Chapter One). Additional mapping of drought/pluvial events would be required to further investigate this potential pattern.

Intra-regional variability was also evident in the growth percentile maps during both drought and pluvial events. Although the chronologies within a particular region typically displayed similar growth percentiles for each drought and pluvial event, this was not always the case. The high intraregional variability is most notable for the Eastern region during the 18541858 drought event and the Western region during the 1829-1830 pluvial event. These results are not particularly surprising considering the local nature of precipitation. Additionally, these results suggest that the four regions identified across the network in Chapter One could be 
unstable during some periods of time. Meko et al. (1993) and Watson and Luckman (2001) indicate that a shifting of circulation anomalies through time could result in more local hydroclimatic variability. Although the four regions identified in Chapter One were found to be mostly stable over longer periods of time, the size and number of regions could be more dynamic on shorter time scales.

It should be noted that the use of individual chronologies to infer spatial patterns of hydroclimate could be problematic due to site-specific disturbance histories. Typically, dendroclimatic studies use multiple tree-ring chronologies, which are combined in some manner, to extract a climate signal and reduce endogenous noise inherent in single chronologies. Though tree-ring chronologies have been analyzed on an individual scale, these studies are usually in the context of a network of chronologies (e.g. Knapp et al. 2004, Nelson et al. 2011). Therefore, the results of the chronology-level growth patterns should not always be viewed as an exact reflection of local and site-specific moisture variability. For example, the drought years of 19421944 appeared to be milder in the Northern region of the network, except for the TN chronology, which displayed an extremely low averaged growth percentile value $\left(<25^{\text {th }}\right.$ percentile $)$ during that time (Fig. 4). Fire data from a neighboring site to TN indicated that 1944 was a severe fire year that scarred nearly all sampled trees (Amy Hessl, personal communication). Despite attempts to avoid fire-disturbed trees, it is likely that this fire event affected the TN chronology; the growth values were relatively high from 1942-1943, but dropped significantly in 1944. Therefore, potential impacts from forest fires, insect defoliations, and other disturbances in Mongolia, should be taken into consideration when analyzing the individual chronology growth patterns mapped here. Nonetheless, these spatial maps provide insight into the relative hydroclimatic variability that could have occurred between and within regions in the network. 


\subsection{The 1999-2002 Droughts}

According to Siurua and Swift (2002) and Batima et al. (2005), the series of summer droughts from 1999-2002 were unprecedented and affected more than half of the Mongolian territory. Our spatial analyses suggest that the 1999-2002 drought event in the Northern region might have not been particularly anomalous within the context of the past two centuries. Our results classify the years 2000-2003 as a drought event which ranked 12th in comparison to other historical droughts. Instrumental data from the northern part of the network also suggest that the recent droughts might have not been completely anomalous in this region. Figure 7 compares streamflow data from the Eruu River with the Northern region time-series from 1959-2008. The 1977-1982 drought event, which ranked as the fourth 'most severe' drought in our analyses, is also evident in the instrumental data. The late-1970s were the most severe (i.e. had the lowest flows) in the streamflow record, however, the most recent droughts (i.e. after 1996) appear to be longer in duration. Interestingly, the time-series from the Northern region does not appear to capture the recent droughts to the same extent as the instrumental data. This could be a function of local differences in climate, or it could be a reflection of our standardization method. "Trend distortion" can occur at the end of a chronology as a consequence of classical standardization techniques (Melvin 2004, Melvin and Briffa 2008). Fitted curves can be biased by short-term disturbances, which can ultimately create an "end-fitting problem" (Melvin 2004, Fang et al. 2010). Potential growth reductions in our tree-ring data associated with the most recent droughts could have influenced the fitted curves used in standardization. This distortion could have inflated the most recent ends of the chronologies, making it appear as though the recent growth reductions were less severe. In order to account for this problem, other methods of 
standardization, particularly the "signal-free" method (Melvin and Briffa 2008) will be considered in future work.

Despite potential limitations in standardization, the severity of recent droughts in the Northern region appeared to be spatially and temporally variable. The ZHU and NTD chronologies only expressed reduced growth from 2000-2003, and the far northern chronologies always had differing responses. Fire could have been responsible for some of the differing responses, particularly for the TN chronology, in which 2000 was a recorded fire year (Amy Hessl, personal communication). Interestingly, the 1995 wet year, followed by the 1996 drought year, were the only hydroclimatic events that were coherent across the entire Northern region. The 1996 droughts and those that potentially followed might have seemed particularly intense, especially considering the relatively wet conditions in each region from 1950-1994. In a drought reconstruction for Mongolia as a whole, Davi et al. (2010) emphasized the regionality of the 1999-2002 droughts. They were particularly severe for parts of central Mongolia, whereas parts of the Altai Mountain range in western Mongolia appeared not to be affected. Although these comparisons are viewed on a broad spatial scale, our analyses indicate that the severe droughts of the late 1990s and early $21^{\text {st }}$ century, as well as other droughts, might have been locally variable as well.

\section{Conclusion}

In this study, we explore the spatial and temporal characteristics of major drought and pluvials across a network of 21 tree-ring chronologies in north-central Mongolia. We illustrate the potential value of using individual chronologies, as well as tree-growth anomaly regions, to evaluate the extent of hydroclimatic variability over the study area. Our results indicate that 
droughts and pluvials have the potential to be spatially extensive, regionalized, or very localized.

The droughts of 1999-2002, in particular, were extremely localized, and appeared to only

influence a few chronologies in some years. This study highlights the importance of investigating

hydroclimatic variability on multiple different temporal and spatial scales. Local spatial scales

might be particularly important and relevant to the livelihoods of Mongolians. Results here could

be used to better investigate the forcings that influence climatic variability on different spatial

scales in Mongolia and the factors that could influence their instability over time.

\section{References}

Angerer, J., G. Han, I. Fujisaki, K. Havstad, 2008. Climate change and ecosystems of Asia with emphasis on Inner Mongolia and Mongolia. Rangelands 30:46-51.

Batima, P., L. Natsagdorj, P. Gombluudev, and B. Erdenetsetseg, 2005. Observed climate change in Mongolia. Assessments and Adaptations to Climate Change (AIACC) Working Paper 12: 1-26 (www.aiaccproject.org).

Biondi, F., T.J. Kozubowski, A. K. Panorska, 2002. Stochastic modeling of regime shifts. Climate Research 23: 23-30.

Biondi, F. T.J. Kozubowki, A.K. Panorska, 2005. A new model for quantifying climate episodes. International Journal of Climatology 25(9): 1253-1264.

Borgford-Parnell, N, 2009. Mongolia: A case for economic diversification in the face of a changing climate. Sustainable Development Law and Policy Vol. 9 Article 18: 54-75.

Brubaker, L.B, 1980. Spatial patterns of tree growth anomalies in the Pacific Northwest. Ecology 61: 798- 807.

Buckley, B. M., K. J. Anchukaitis, D. Penny, R. Fletcher, E. R. Cook, M. Sano, L. C. Nam, A. Wichienkeeo, T. T. Minh, and T. M. Hong, 2010. Climate as a contributing factor in the demise of Angkor, Cambodia, Proceedings of the National Academy of Sciences of the United States of America, 107(15), 5.

Cook, E.R. ,1985. A time-series analysis approach to tree-ring standardization. PhD dissertation, The University of Arizona Press, Tucson, $171 \mathrm{pp}$. 
Cook E.R. and K. Peters, 1997. Calculating unbiased tree-ring indices for the study of climatic and environmental change. The Holocene 7: 361-370.

Davi, N.K., G.C. Jacoby, A.E. Curtis and B. Nachin, 2006. Extension of drought records for central Asia using tree-rings: west-central Mongolia. Journal of Climate 19: 288-299.

Davi, N.K., G. Jacoby, R. D’Arrigo, N. Baatarbileg, L. Jinbao, A.E. Curtis, 2009. A tree-ringbased drought index reconstruction for far-western Mongolia: 1565-2004. International Journal of Climatology, 29: 1508-1514.

Davi, G. Jacoby, K. Fang, J. Li, R. D’Arrigo, N. Baatarbileg, D. Robinson, 2010. Reconstructing drought variability for Mongolia based on large-scale tree-ring network: 1520-1993. Journal of Geophysical Research, 115, D22103, doi:10.1029/2010JD013907.

Endo, N., T. Kadota, J. Matsumoto, B. Ailikun, T. Yasunari, 2006. Climatology and trends in summer precipitation characteristics in Mongolia for the period 1960-1998. Journal of the Meteorological Society of Japan 84(3): 543-551.

Fang, K., X. Gou, K. Peters, J. Li, F. Zhang, 2010. Removing biological growth trends from treering series: testing modified Hugershoff curves. Tree-ring Research 66(1): 51-59.

Friedman J.H., 1984. A variable span smoother (Laboratory for Computational Statistics, Department of Statistics, Stanford University, Stanford, CA) Technical Report 5.

Gou, X., F. Chen, E. Cook, G. Jacoby, M. Yang, J. Li, 2007. Streamflow variations of the Yellow River over the past 593 years in western China reconstructed from tree rings. Water Resources Research 43, W06434, doi:10.1029/2006WR005705.

Gray, S.T., S.T. Jackson, J.L. Betancourt, 2004. Tree-ring based reconstructions of interannual to decadal-scale precipitation variability for Northeastern Utah. Journal of the American Water Resources Association (JAWRA) 40: 947-960.

Gray, S.T., J.L. Lukas, C.A. Woodhouse, 2011. Millennial-length records of streamflow from three major upper Colorado River tributaries. Journal of the American Water Resources Association (JAWRA) 1-11 doi: 10.1111/j.1752-1688.2011.00535.x.

Hintze, J.L., and R.D. Nelson, 1998. Violin plots: A box plot-density trace synergism. The American Statistician 52(2): 181-184.

Holmes, R. L., 1983. Computer assisted quality control in tree-ring dating and measurement. Tree-ring Bulletin, 43: 69-78.

Kim, B.S., S.Z. Hossein, G. Choi, 2011. Evaluation of temporal-spatial precipitation variability and prediction using seasonal ARIMA Model in Mongolia. KSCE Journal of Civil Engineering 15(5): 917-925. 
Knapp, P.A., P.T Soule, H.D. Grissino-Mayer, 2004. Occurrence of sustained droughts in the interior Pacific Northwest (A.D. 1733-1980) inferred from tree-ring data. Journal of Climate 17: 140-150.

Li, J., F. Chen, E.R. Cook, X. Gou, Y. Zhang, 2007. Drought reconstruction for north central China from tree rings: the value of the Palmer drought severity index. International Journal of Climatology 27: 903-909.

Li, J., E.R. Cook, R. D’arrigo, F. Chen, X. Gou, 2009. Moisture variability across China and Mongolia: 1951-2005. Climate Dynamics 32: 1173-1186.

Liang, E., X. Shao, Z. Kong, J. Lin, 2003. The extreme drought in the 1920s and its effect on tree growth deduced from tree ring analysis: a case study in North China. Ann. For. Sci. 60: 145-152.

Lorimer, C.G., and L.E. Frelich, 1989. A methodology for estimating canopy disturbance frequency and intensity in dense temperate forests. Canadian Journal of Forest Research 19: 651-663.

Marin, A, 2010. Riders under storms: Contributions of nomadic herders' observations to analysing climate change in Mongolia. Global Environmental Change 20: 162-176.

Meko, D., E.R. Cook, D.W. Stahle, C.W. Stockton, M.K. Holmes, 1993. Spatial patterns of treegrowth anomalies in the United States and Southeastern Canada. Journal of Climate 6(9): 1773-1786.

Melvin, T.M., 2004. Historical growth rates and changing climatic sensitivity of boreal confers. Thesis, University of East Anglia <http://www.cru.uea.as.uk/cru/pubs/thesis/2004melvin/>.

Melvin, T.M., K.R. Briffa, 2008. A "signal-free" approach to dendroclimatic standardization. Dendrochronologia 26: 71-86.

Nelson, T.A., C.P. Laroque, D.J. Smith, 2011. Detecting spatial connections within a dendrochronological network on Vancouver Island, British Columbia. Dendrochronologia 29: 49-54.

Pederson, N., G.C. Jacoby, R.D. D’Arrigo, E.R. Cook, and B. Buckley, 2001. Hydrometeorological reconstructions for Northeastern Mongolia derived from tree-rings: 1651-1995. Journal of Climate 14: 872-881.

Pederson, N., E.R. Cook, G.C. Jacoby, D.M. Peteet, K.L. Griffin, 2004. The influence of winter temperatures on the radial growth of six northern range margin tree species.

Dendrochronologia 22: 7-29. 
Pederson, G.T., S.T. Gray, D.B. Fagre, L.J. Graumlich, 2006. Long-duration drought variability and impacts on ecosystem services: a case study from Glacier National Park, Montana. Earth Interactions 10 (4): 1-28.

Qian, W., X. Lin, Y. Zhu, Y. Xu, J. Fu, 2007. Climatic regime shift and decadal anomalous events in China. Climatic Change 84: 167-189.

Salas, J.D., J.W. Delleur, V. Yevjevich, W.L. Lane, 1980. Applied Modeling of Hydrologic Time Series. Water Resources Publications, Littleton Colorado.

Sato, T. F, Kimura, A. Kitoh, 2004. Cloud frequency in eastern Mongolia and its relation to orography. Proceedings of the Third International Workshop on Terrestrial Change in Mongolia, Ulan Bator: 107-109.

Sato, T., F. Kimura, A. Kitoh, 2007. Projection of global warming onto regional precipitation over Mongolia using a regional climate model. Journal of Hydrology 333: 144-154.

Shao, X., L. Huang, H. Liu, 2005. Reconstruction of precipitation variation from tree-rings in recent 1000 years in Delingha, Qinghai. Science in China, Series D: Earth Science 48(7): 939-949.

Siurua, H., and J. Swift., 2002. Drought and zud but no famine (yet) in the Mongolian herding economy. IDS Bulletin, 33(4): 88-97.

Sternberg, T., D. Thomas, N. Middleton, 2010. Drought dynamics on the Mongolian steppe, 1970-2006. International Journal of Climatology, 31: doi: 10.1002/joc.2195.

Stokes, M. and T. Smiley, 1968. An introduction to tree-ring dating, Tucson, AZ: University of Arizona Press.

Watson, E. and B.H. Luckman, 2001. The development of a moisture-stressed tree-ring chronology network for the southern Canadian Cordillera. Tree-Ring Research 57: 149168.

Zhang, J., and Z. Lin, 1992. Climate of China. Wiley, 376 pp. 
Table 1. List of site chronologies in the tree-ring network (also in Chapter One). The asterisks refer to chronologies that were collected most recently.

\begin{tabular}{l|l|c|l|c|c}
\hline SITE NAME & CODE & ALT $(\mathbf{m})$ & \multicolumn{1}{c}{ SPECIES } & \# TREES & YEARS \\
\hline Bugant* & BG & 1027 & P. sylvestris & 19 & $1730-2008$ \\
Dadal & DR & 1020 & P. sibirica & 15 & $1704-2001$ \\
Delger Khan Uul* & DKH & 1247 & P. sylvestris & 13 & $1710-2009$ \\
Dulaankhan* & DKN & 1180 & P. sylvestris & 20 & $1653-2008$ \\
Inferno Ridge & IR & 900 & P. sibirica & 19 & $1692-1996$ \\
Khorgo Lava Larch & KLL & 2060 & L. sibirica & 39 & $1340-2000$ \\
Khorgo Lava Pine* & KLP & 2077 & P. sibirica & 13 & $1422-2009$ \\
Manzshir Hiid & MH & 1755 & P. sibirica & 8 & $1505-1994$ \\
Narstain Davaa* & NTD & 1548 & P. sylvestris & 11 & $1740-2008$ \\
Onon Gol & ONG & 1012 & L. sibirica & 16 & $1576-2001$ \\
Orkhon Gol Hushree* & OGH & 1829 & L. sibirica & 15 & $1503-2009$ \\
Suulchyin Medee & SM & 1419 & L. sibirica & 15 & $1557-2002$ \\
Shaamar Mahan Nars* & SMN & 650 & P. sylvestris & 9 & $1770-2008$ \\
Terelj & TJ & 1669 & L. sibirica & 16 & $1590-2002$ \\
Tujyin Nars* & TNC & 750 & P. sylvestris & 12 & $1731-2008$ \\
Uglugchiin Herem* & UGH & 1416 & P. sylvestris & 9 & $1705-2009$ \\
Under Ulaan & UU & 1545 & L. sibirica & 15 & $1510-2002$ \\
Urgun Nars & UN & 1070 & P. sylvestris & 15 & $1651-1996$ \\
Zurkh Uul* & ZHU & 1228 & P. sylvestris & 14 & $1714-2009$ \\
Zuun Mod & ZM & 1415 & L. sibirica & 26 & $1582-2000$ \\
Zuun Salaa Mod & ZSM & 1900 & L. sibirica & 20 & $1513-2001$ \\
\hline
\end{tabular}


Table 2. Top-five drought events identified by a runs analysis for each region. The different colors indicate the drought events in common between regions. The first rank was the most 'severe' drought event for each region (i.e. highest scoring).

\begin{tabular}{|c|c|c|c|c|}
\hline Rank & Eastern: & Western: & Northern: & Central: \\
\hline \multirow{2}{*}{1} & 1942-1944 & 1854-1858 & $1822-1825$ & $1928-1930$ \\
\hline & $38 \%$ & $24 \%$ & $33 \%$ & $62 \%$ \\
\hline \multirow{2}{*}{2} & $1801-1802$ & $1839-1840$ & 1928-1929 & $1942-1943$ \\
\hline & $38 \%$ & $48 \%$ & $76 \%$ & $33 \%$ \\
\hline 3 & $\begin{array}{c}1791-1795 \\
24 \%\end{array}$ & $\begin{array}{c}1977-1981 \\
62 \%\end{array}$ & $\begin{array}{c}1844-1845 \\
52 \%\end{array}$ & $\begin{array}{c}1814-1815 \\
33 \%\end{array}$ \\
\hline \multirow{2}{*}{4} & $1874-1879$ & $1809-1810$ & $1977-1982$ & $1839-1840$ \\
\hline & $14 \%$ & $24 \%$ & $38 \%$ & $48 \%$ \\
\hline \multirow{2}{*}{5} & $1928-1932$ & $1900-1905$ & 1903-1906 & $1978-1981$ \\
\hline & $29 \%$ & $29 \%$ & $52 \%$ & $76 \%$ \\
\hline
\end{tabular}

Table 3. Top-five pluvial events identified by a runs analysis for each region. The different colors indicate the pluvial events in common between regions. The first rank was the most 'severe' pluvial event for each region (i.e. highest scoring).

\begin{tabular}{|c|c|c|c|c|}
\hline Rank & Eastern: & Western: & Northern: & Central: \\
\hline \multirow{2}{*}{1} & $1829-1830$ & 1916-1917 & 1826-1831 & $1958-1960$ \\
\hline & $71 \%$ & $38 \%$ & $33 \%$ & $48 \%$ \\
\hline \multirow{2}{*}{2} & $1933-1938$ & $1990-1993$ & 1985-1986 & $1915-1917$ \\
\hline & $24 \%$ & $24 \%$ & $48 \%$ & $33 \%$ \\
\hline \multirow{2}{*}{3} & $1812-1814$ & $1795-1799$ & $1812-1814$ & $1895-1896$ \\
\hline & $48 \%$ & $24 \%$ & $48 \%$ & $43 \%$ \\
\hline \multirow{2}{*}{4} & $1908-1912$ & $1801-1803$ & $1962-1964$ & $1828-1831$ \\
\hline & $43 \%$ & $29 \%$ & $57 \%$ & $57 \%$ \\
\hline \multirow{2}{*}{5} & $1837-1838$ & $1943-1944$ & $1890-1891$ & $1812-1813$ \\
\hline & $67 \%$ & $24 \%$ & $38 \%$ & $52 \%$ \\
\hline
\end{tabular}


Table 4. Correlations between tree-growth anomaly regions (also in Chapter One). Asterisks indicate that the correlation coefficient is significant at the $\mathrm{p}<0.05$ level.

\begin{tabular}{l|cccc}
\hline & Eastern & Western & Northern & Central \\
\hline Eastern & --- & & & \\
Western & 0.026 & --- & & \\
Northern & $0.383^{*}$ & $0.251^{*}$ & --- & - \\
Central & $0.380^{*}$ & $0.238^{*}$ & $0.439^{*}$ & -- \\
\hline
\end{tabular}

Table 5. Cumulative runs analysis drought scores.

\begin{tabular}{lccccc}
\hline & Eastern & Western & Northern & Central & Total \\
\hline $\mathbf{1 8 0 0 - 1 8 4 9}$ & 388 & 446 & 414 & 495 & 1743 \\
$\mathbf{1 8 5 0 - 1 8 9 9}$ & 395 & 283 & 466 & 465 & 1609 \\
$\mathbf{1 9 0 0 - 1 9 4 9}$ & $419 *$ & 405 & 475 & 511 & 1810 \\
$\mathbf{1 9 5 0 - 1 9 9 4}$ & 332 & 106 & 135 & 321 & 960 \\
\hline
\end{tabular}

*The 1949-1952 drought of the Eastern region was considered only in the 1900-1949 period.

Table 6. Cumulative runs analysis pluvial scores.

\begin{tabular}{lccccc}
\hline & Eastern & Western & Northern & Central & Total \\
\hline $\mathbf{1 8 0 0 - 1 8 4 9}$ & 662 & 323 & 325 & 581 & 1891 \\
$\mathbf{1 8 5 0 - 1 8 9 9}$ & 396 & 222 & 516 & 333 & 1467 \\
$\mathbf{1 9 0 0 - 1 9 4 9}$ & 386 & 592 & 440 & $449 *$ & 1867 \\
$\mathbf{1 9 5 0 - 1 9 9 4}$ & 487 & 517 & 537 & 466 & 2063 \\
\hline
\end{tabular}

*The 1949-1950 pluvial of the Central region was considered only in the 1900-1949 period. 
Fig. 1. Map of tree-ring chronology network. The light gray represents forest cover. LASI $=L$. sibirica ; PISI $=$ P. sibirica $;$ PISY $=P$. sylvestris . Purple $=$ Western region; Red $=$ Central region; Blue $=$ Northern region; Green $=$ Eastern region .

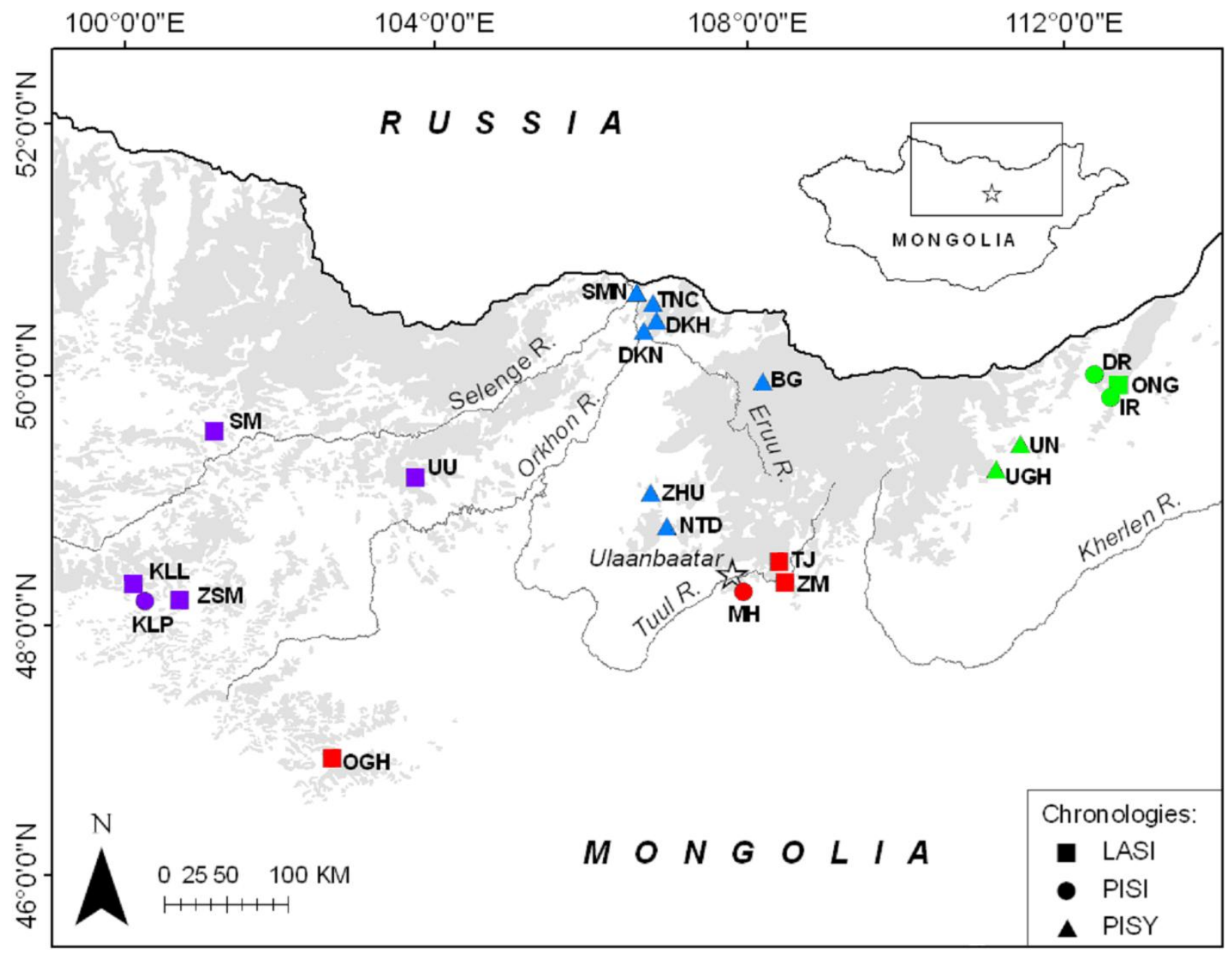


Fig. 2. PC1 scores for each region (also in Chapter One). Positive PC scores represent aboveaverage growth, and negative PC scores indicate below-average growth. The bold red lines are an 11-year lowess-smoothing of each time-series.

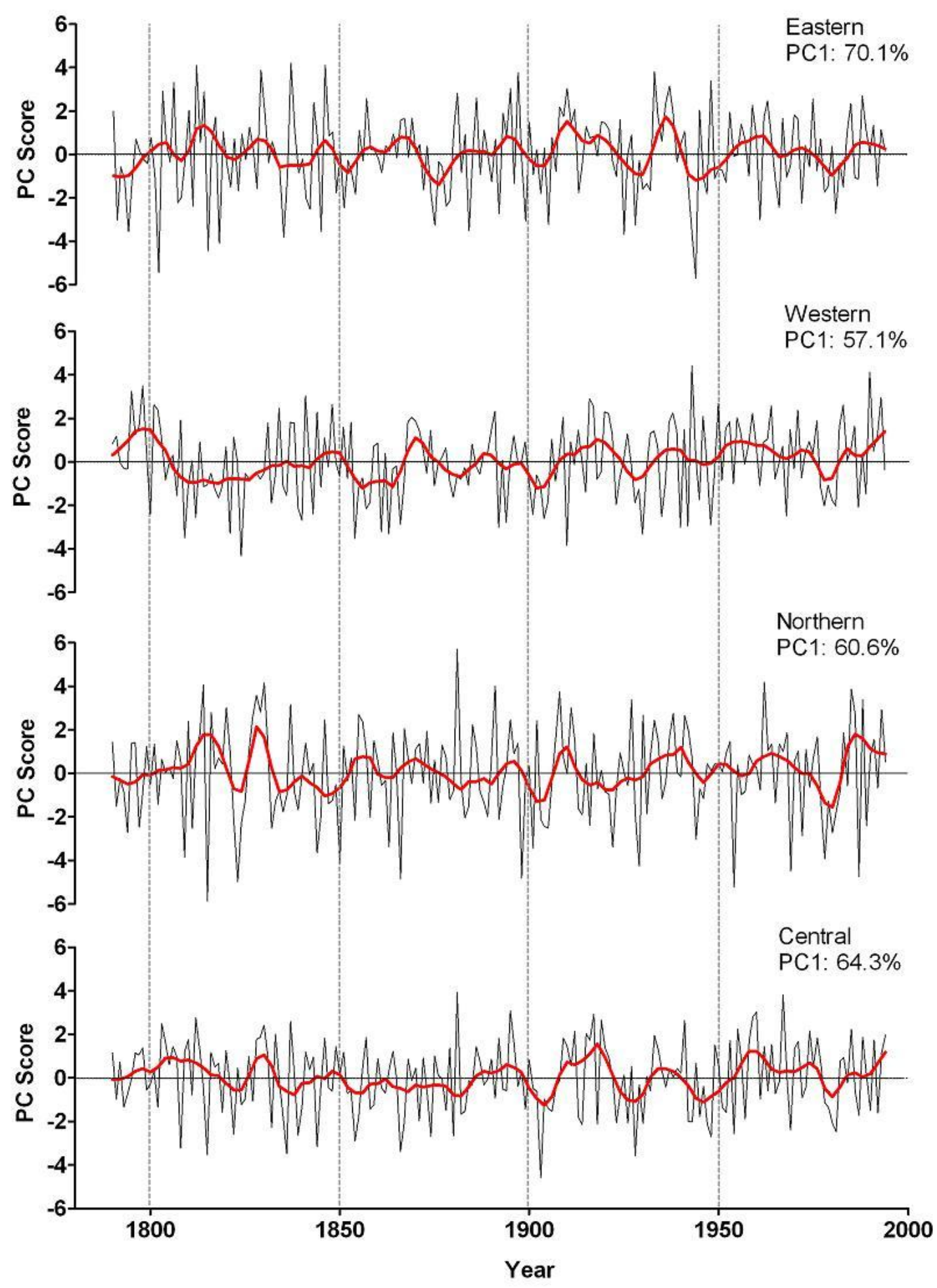


Fig. 3. Violin plots for each region in $~ 50$-year subsets. The plots display the distribution of regional PC scores over time.
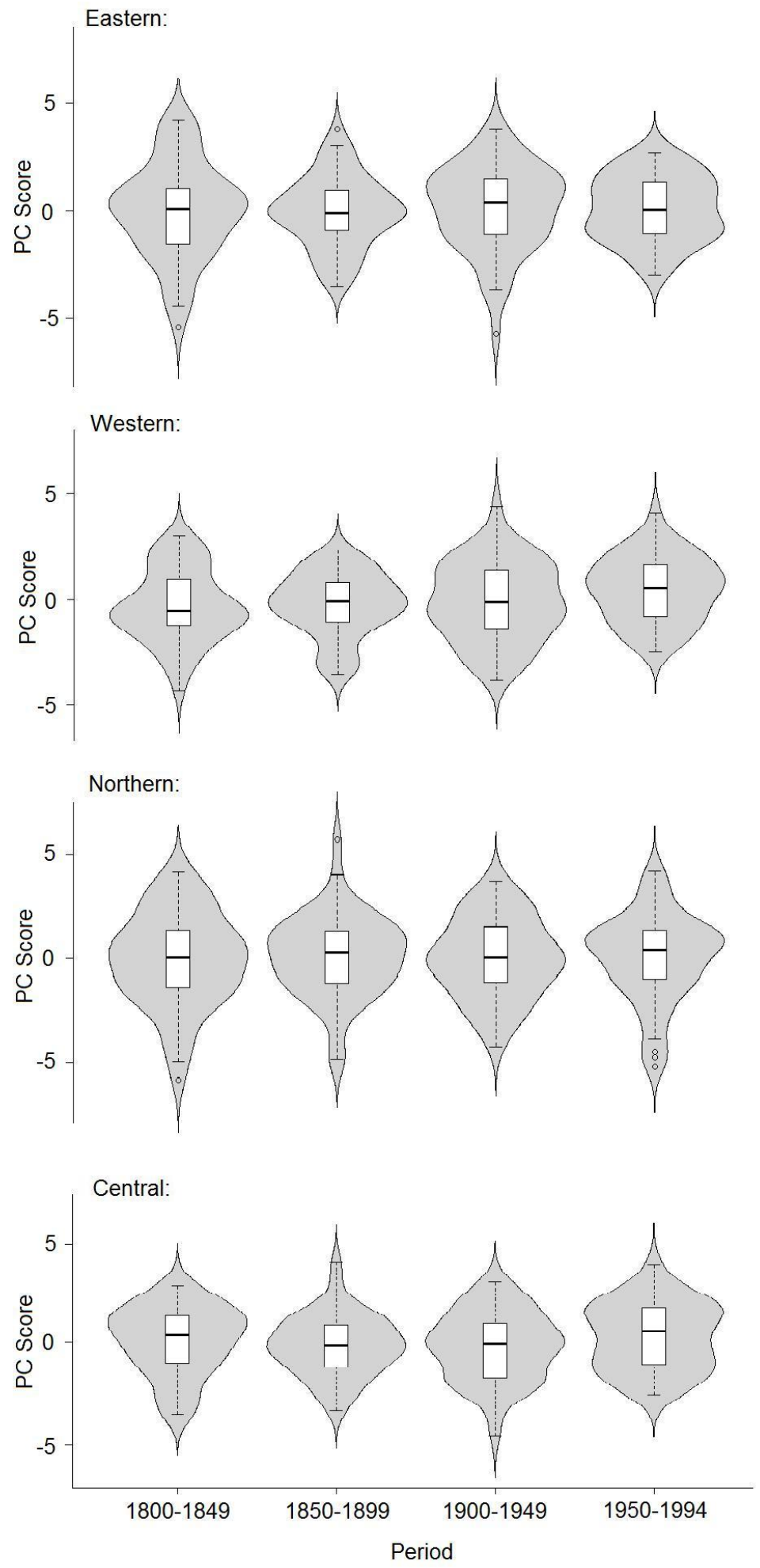
Fig. 4. Maps of top-scoring drought events. The years associated with each event are listed in the legend of each map. Warm colors indicate a low growth percentile (i.e. inferred drought conditions), and cool colors indicate a high growth percentile (i.e. inferred wet conditions).
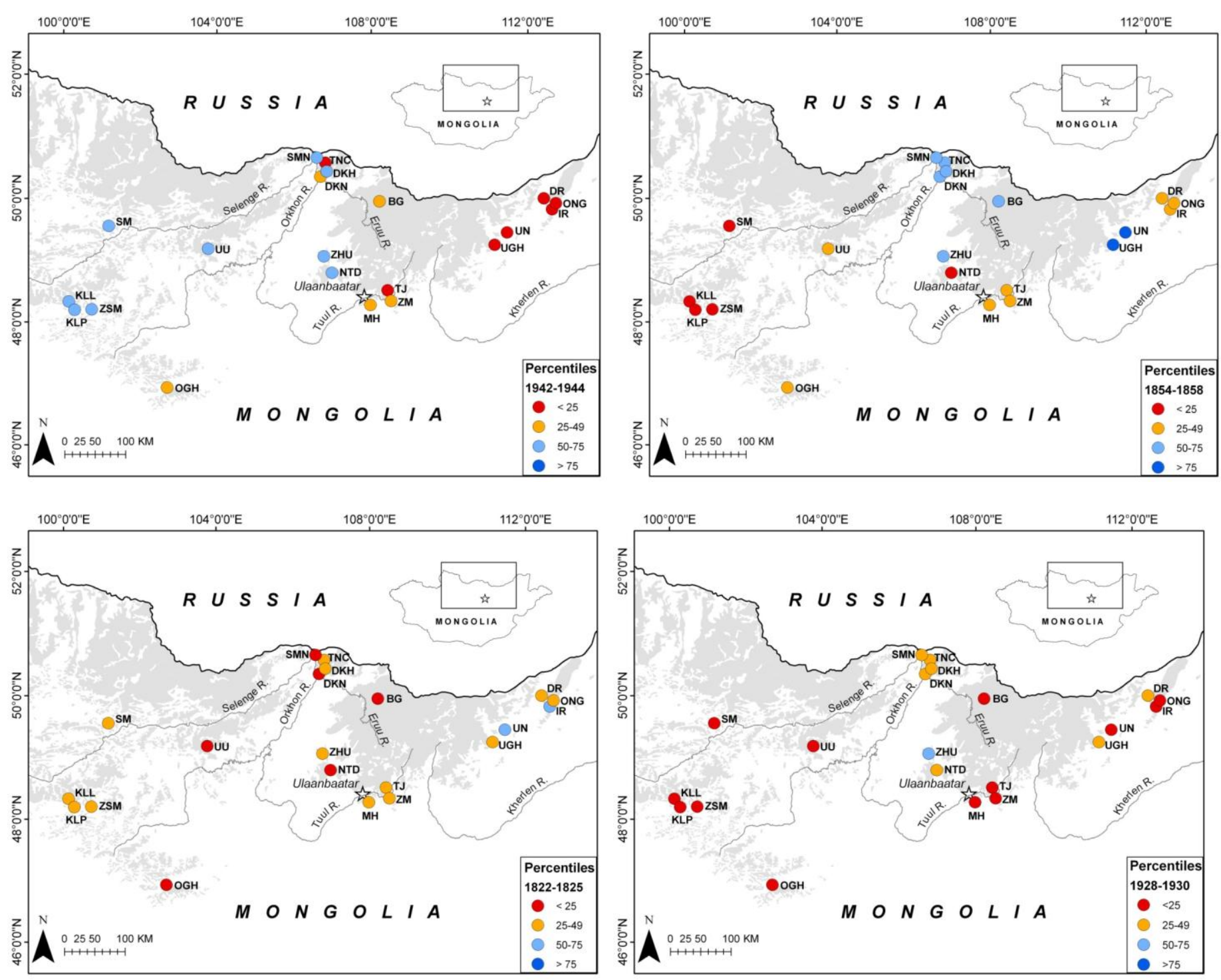
Fig. 5. Maps of top-scoring pluvial events. The years associated with each event are listed in the legend of each map. Warm colors indicate a low growth percentile (i.e. inferred drought conditions), and cool colors indicate a high growth percentile (i.e. inferred wet conditions).
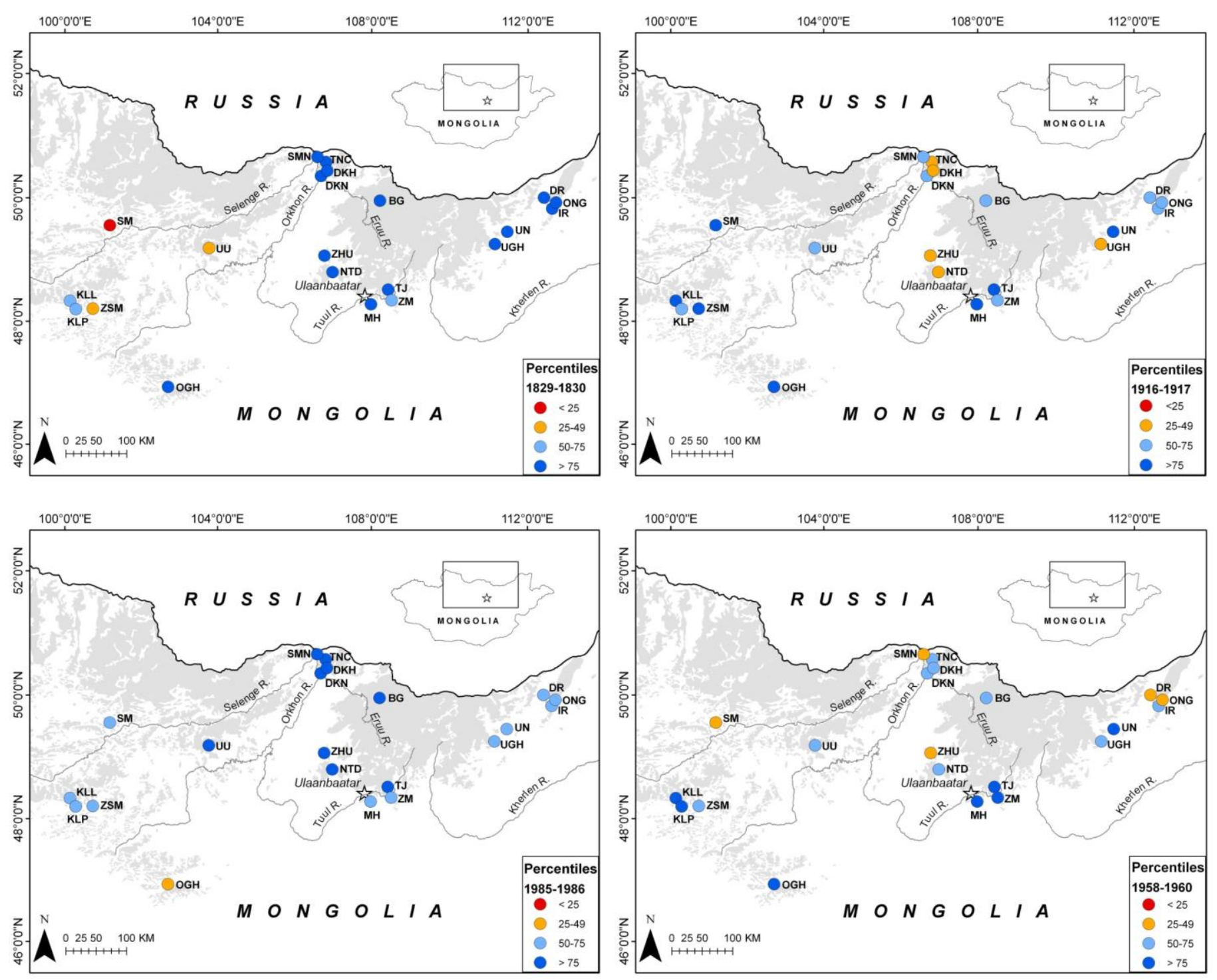
Fig. 6. Growth percentile maps for the years 1995-2002. The legend for all figures is located on the 2002 map on the bottom right. Red ( $<25$ th percentile); orange (25-49th percentile); light blue (50-75th percentile); dark blue ( $>75^{\text {th }}$ percentile).
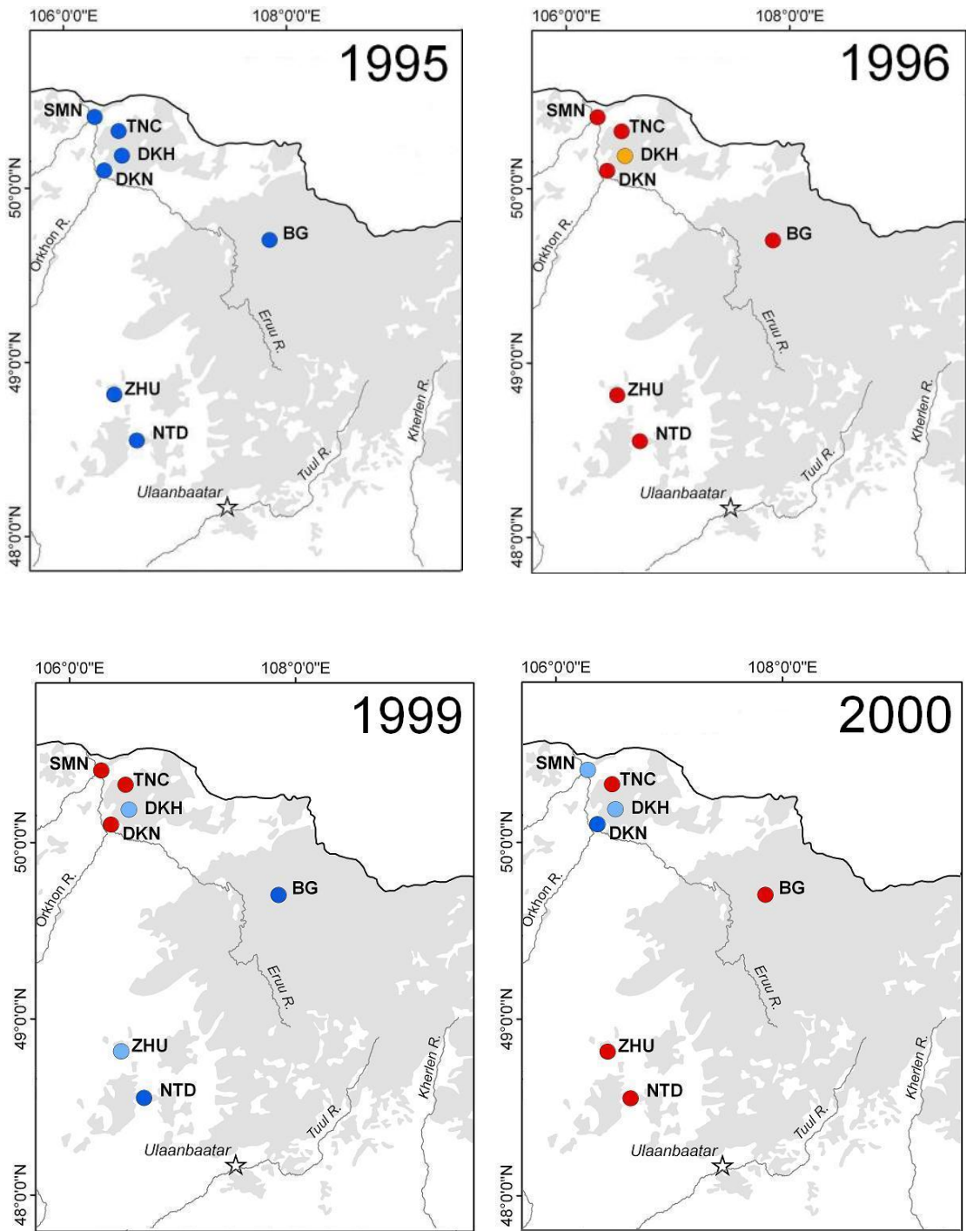
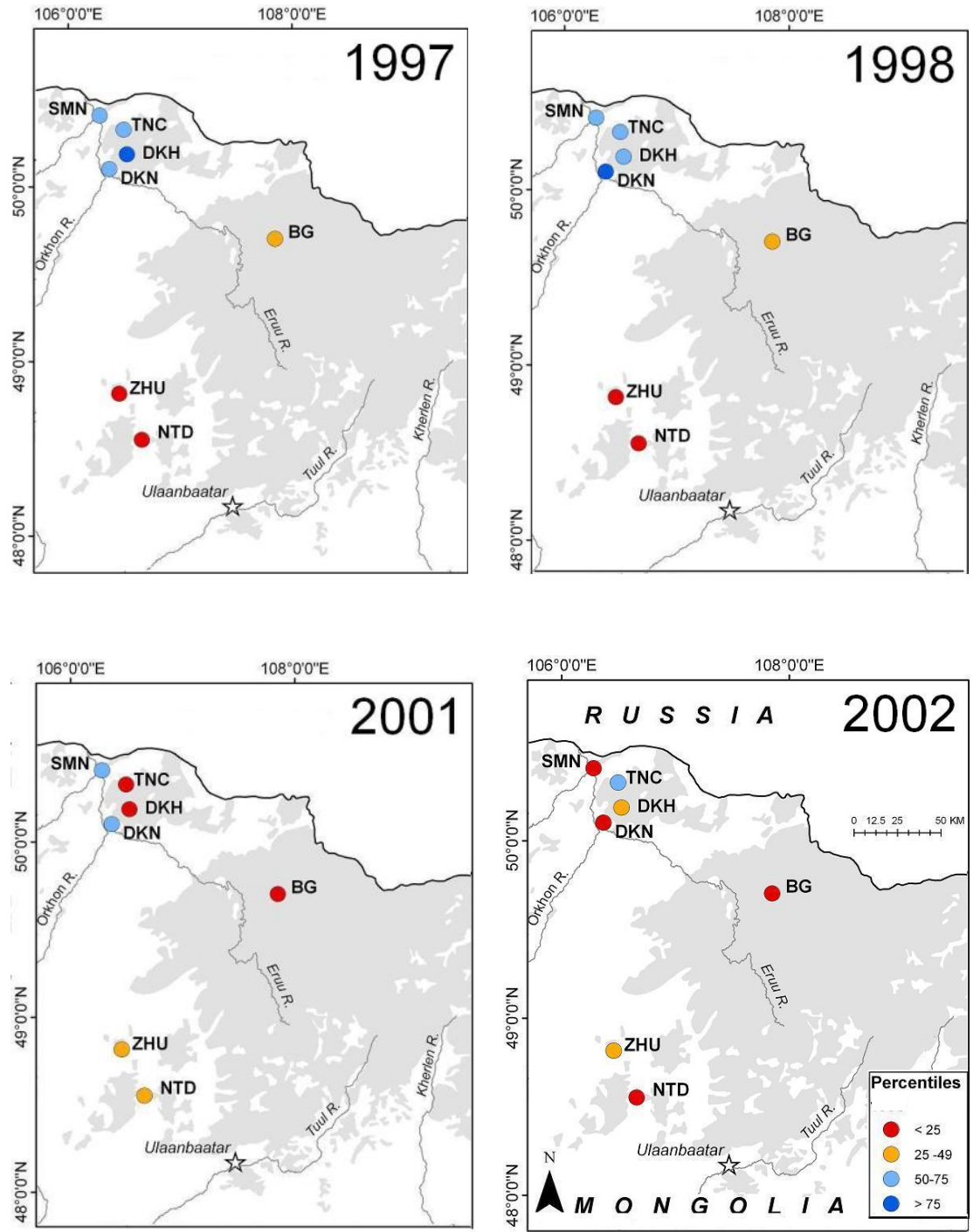
Fig. 7. Eruu River streamflow (top) and PC scores for the Northern region (bottom) from 19592008.
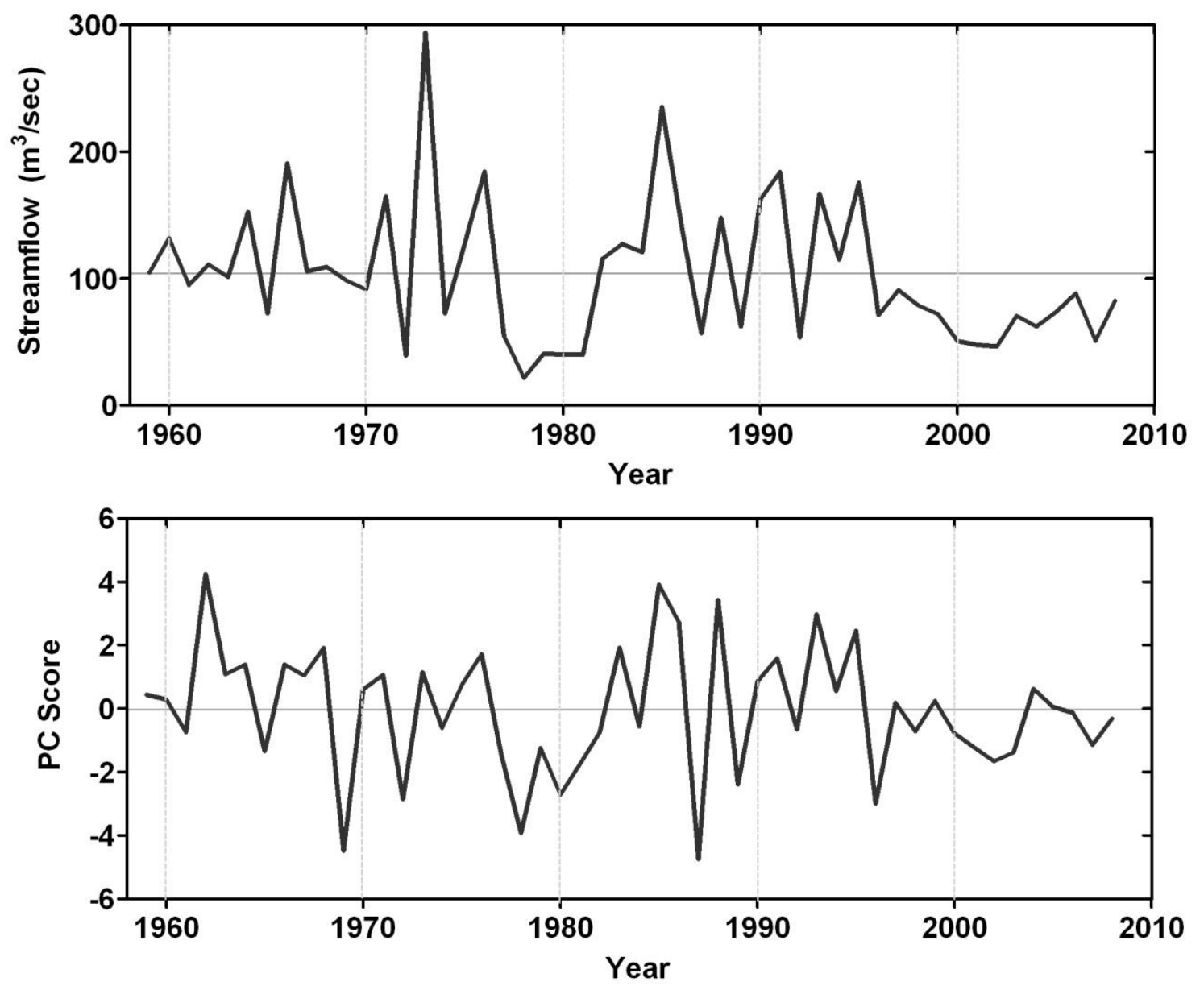


\section{Appendix}

Appendix A. Top-five drought events for each region. a) Eastern; b) Western; c) Northern; d) Central

a) Eastern Region:

\begin{tabular}{ccccc}
\hline Drought Event & Duration & Magnitude & Intensity & Total Score \\
\hline $1942-1944$ & 3 & -10.864 & -3.621 & 109 \\
$1801-1802$ & 2 & -6.482 & -3.241 & 103 \\
$1791-1795$ & 5 & -9.369 & -1.874 & 99 \\
$1874-1879$ & 6 & -10.491 & -1.749 & 95 \\
$1928-1932$ & 5 & -8.104 & -1.621 & 89 \\
\hline
\end{tabular}

b) Western Region:

\begin{tabular}{ccccc}
\hline Drought Event & Duration & Magnitude & Intensity & Total Score \\
\hline $1854-1858$ & 5 & -9.256 & -1.851 & 90 \\
$1839-1840$ & 2 & -4.691 & -2.346 & 87 \\
$1977-1981$ & 5 & -7.773 & -1.555 & 84 \\
$1809-1810$ & 2 & -4.576 & -2.288 & 83 \\
$1900-1905$ & 6 & -9.031 & -1.505 & 82 \\
\hline
\end{tabular}

c) Northern Region:

\begin{tabular}{ccccc}
\hline Drought Event & Duration & Magnitude & Intensity & Total Score \\
\hline $1822-1825$ & 4 & -11.161 & -2.790 & 100 \\
$1928-1929$ & 2 & -6.455 & -3.228 & 98 \\
$1844-1845$ & 2 & -5.943 & -2.972 & 94 \\
$1977-1982$ & 6 & -12.753 & -2.126 & 93 \\
$1903-1906$ & 4 & -7.975 & -1.994 & 89 \\
\hline
\end{tabular}

d) Central Region:

\begin{tabular}{ccccc}
\hline Drought Event & Duration & Magnitude & Intensity & Total Score \\
\hline $1928-1930$ & 3 & -5.950 & -1.983 & 96 \\
$1942-1943$ & 2 & -3.999 & -2.000 & 95 \\
$1814-1815$ & 2 & -3.994 & -1.997 & 93 \\
$1839-1840$ & 2 & -3.976 & -1.998 & 91 \\
$1978-1981$ & 4 & -7.003 & -1.751 & 91 \\
\hline
\end{tabular}


Appendix B. Top-five pluvial events for each region. a) Eastern; b) Western; c) Northern; d) Central

a) Eastern Region:

\begin{tabular}{ccccc}
\hline Pluvial Event & Duration & Magnitude & Intensity & Total Score \\
\hline $1829-1830$ & 2 & 5.907 & 2.954 & 107 \\
$1933-1938$ & 6 & 13.634 & 2.272 & 106 \\
$1812-1814$ & 3 & 7.569 & 2.523 & 105 \\
$1908-1912$ & 5 & 10.486 & 2.097 & 104 \\
$1837-1838$ & 2 & 5.209 & 2.605 & 103 \\
\hline
\end{tabular}

b) Western Region:

\begin{tabular}{ccccc}
\hline Pluvial Event & Duration & Magnitude & Intensity & Total Score \\
\hline $1916-1917$ & 2 & 5.573 & 2.787 & 97 \\
$1990-1993$ & 4 & 8.981 & 2.245 & 97 \\
$1795-1799$ & 5 & 10.200 & 2.040 & 96 \\
$1801-1803$ & 3 & 6.168 & 2.056 & 93 \\
$1943-1944$ & 2 & 4.862 & 2.431 & 93 \\
\hline
\end{tabular}

c) Northern Region:

\begin{tabular}{ccccc}
\hline Pluvial Event & Duration & Magnitude & Intensity & Total Score \\
\hline $1826-1831$ & 6 & 14.53 & 2.422 & 106 \\
$1985-1986$ & 2 & 6.276 & 3.138 & 106 \\
$1812-1814$ & 3 & 6.436 & 2.145 & 99 \\
$1962-1964$ & 3 & 6.186 & 2.062 & 94 \\
$1890-1891$ & 2 & 4.442 & 2.221 & 92 \\
\hline
\end{tabular}

d) Central Region:

\begin{tabular}{ccccc}
\hline Pluvial Event & Duration & Magnitude & Intensity & Total Score \\
\hline $1958-1960$ & 3 & 7.572 & 2.524 & 108 \\
$1915-1917$ & 3 & 6.731 & 2.244 & 102 \\
$1895-1896$ & 2 & 4.690 & 2.345 & 101 \\
$1828-1831$ & 4 & 7.060 & 1.765 & 98 \\
$1812-1813$ & 2 & 4.076 & 2.038 & 97 \\
\hline
\end{tabular}


Appendix C. Results from t-tests; testing for a significant difference between the means of two periods of time (1900-1949 and 1950-1994) for each region. The regional PC scores for all periods of time were normally distributed as determined by a Shapiro-Wilks test ( $>0.05)$.

\begin{tabular}{c|c|c|c|c}
\hline & Eastern & Western & Northern & Central \\
\hline$t$-statistic & 0.087 & -1.743 & -0.076 & -1.435 \\
$p$-value & 0.93 & 0.08 & 0.94 & 0.15 \\
\hline
\end{tabular}

Appendix D. Results from an ANOVA; testing for a significant difference between the means of all periods of time (1800-1849; 1850-1899; 1900-1949; 1950-1994) for each region. The regional PC scores for all periods of time were normally distributed as determined by a ShapiroWilks test $(\mathrm{p}>0.05)$.

\begin{tabular}{c|c|c|c|c}
\hline & Eastern & Western & Northern & Central \\
\hline F-statistic & 0.093 & 2.264 & 0.002 & 0.454 \\
$p$-value & 0.96 & 0.08 & 0.99 & 0.45 \\
\hline
\end{tabular}




\section{SUMMARY}

The four tree-growth anomaly regions identified in Chapter One were found to be relatively stable over time and space from 1790-1994. Although these tree-growth anomaly regions provide valuable insight into how hydroclimate varies across the current tree-ring network in north-central Mongolia, it is important to keep in mind that our results are sensitive to the number and location of chronologies considered in the network. Correlation analyses suggest that the tree-growth anomalies are a reflection of hydroclimatic variability within the study area, though the statistical relationship between tree-growth anomalies and streamflow data might have been better supported if more instrumental records had been available, or if the instrumental records were longer.

Chapter Two illustrates the differences in inferred hydroclimatic variability between the four tree-growth anomaly regions. In examining the top-five major drought and pluvial events for each region, inter-regional climatic variability was evident. Through correlation analyses and maps of major hydroclimatic events, it is clear that the Eastern and Western regions are the most unique from one another. Although it appears as though the major drought and pluvial events associated with the Northern and Central regions of the network are broader in scale than some of those associated with the Eastern and Western regions of the network, more analyses are needed to come to this conclusion. Our findings also demonstrate high levels of intra-regional climatic variability across the tree-ring network, especially for the drought events associated with the late-1990s and early-2000s. However, these results should be accepted cautiously, as individual tree-ring chronologies are often 'noisy', and are not always an exact reflection of sitespecific moisture variability. 
Future work should focus on: 1) filling in the current network of tree-ring chronologies, particularly for the Western region of the network and the Khentii mountains; 2) using the results of these analyses to develop hydroclimatic reconstructions for areas within the network that have not yet been studied from a paleoclimatic perspective, such as the Northern region; 3) attempting new forms of standardization for evaluating the recent droughts (i.e. 1999-2002) in the tree-ring record ; and 4) understanding the forcings that influence climatic variability on regional and local scales in Mongolia. 


\section{Caroline W. Leland}

Permanent Address: 5801 Robin's Nest Court • Burke, VA 22015

Phone: (703)786-1148

E-mail: carolineleland@gmail.com

\section{EDUCATION}

West Virginia University

Master of Arts, Geography, Research Assistant

Aug. $2010-2011$

- Thesis title: Hydroclimatic Variability in North-central Mongolia as Inferred from Tree Rings

- Thesis advisors: Drs. Neil Pederson and Amy Hessl

- Cumulative GPA: 4.0

Eastern Kentucky University

Master of Science, Biology (Applied Ecology), Research Assistant

Aug. 2009 - May 2010

- Cumulative GPA: 4.0

- Advisor: Dr. Neil Pederson

West Virginia University

Bachelor of the Arts, Environmental Geoscience

Aug. 2005 - May 2009

- Dean's List: 2005-2006, President's List: Fall 2006, 2007 and Spring 2007, 2008, 2009

- Cumulative GPA: 3.9

- Senior Thesis: Dendrochronological Applications for Climate Reconstruction using Eastern Redcedar

\section{PRESENTATIONS}

- Leland, C., N. Pederson. 2011. Hydroclimatic Regionalization in North-central Mongolia as Inferred from Tree-Rings. No Boundaries Conference, The Pennsylvania State University, March 2011, University Park, Pennsylvania.

- Leland, C., N. Pederson, A. Hessl, B. Nachin, P. Brown, T. Saladyga, B. Suran. 2010. Fire and Climate Interactions in Northeastern Mongolia. Annual Meeting, Association of Southeastern Biologists, 7-10 April 2010, Asheville, NC.

- Leland, C., N. Pederson, A. Hessl. 2009. Tree-Ring Applications for Climate Reconstruction using Eastern Redcedar: An Exploratory Study. Annual Meeting, Kentucky Academy of Science, 13 November 2009, Northern Kentucky University, KY.

- Leland, C. A. Hessl. 2009. Tree-Ring Applications for Climate Reconstruction using Eastern Redcedar: An Exploratory Study (poster). Annual Meeting, No Boundaries Geography Conference, 28 February - 1 March 2009, Pennsylvania State University, PA.

- Leland, C. A. Hessl. 2009. Tree-Ring Applications for Climate Reconstruction using Eastern Redcedar: An Exploratory Study (poster). Undergraduate Research Day at the Capitol, 28 January 2010, Charleston, WV. 


\section{EXPERIENCE}

\section{WVU Department of Geography}

Graduate Research

June 2010 - Aug. 2010

- Conducted dendroecological fieldwork and research in Mongolia

EKU Department of Biological Sciences

Aug. 2009 - May 2010

Graduate Research

- Investigated Mongolian climate through tree-ring analysis as a Research Assistant

- Performed tree-ring analysis on an archaeological sample from Chester County, Pennsylvania

WVU Department of Geography

Undergraduate Research/Research Assistant

May 2007 - May 2009

- Conducted research on data obtained as an undergraduate research assistant

- Analyzed tree cores and cross sections of Eastern Redcedar to determine paleoclimate conditions and trends in the Potomac River Watershed

\section{North American Dendroecological Fieldweek (NADEF)}

WVU Amizade Study Abroad

Service Learning in Patagonia

Oct. 2007 - Feb. 2010

- Created a documentary emphasizing the negative impacts of proposed hydroelectric dams in southern Chile

\section{AWARDS}

- $\quad$ Member of Phi Beta Kappa (inducted spring 2009)

- Outstanding Senior for the Environmental Geosciences Program at WVU (2009)

- Golden Key Honor Society - International academic honor society awarded to top $15 \%$ of class 